\title{
Physical and Compaction Properties of Granular Materials with Artificial Grading behind the Particle Size Distributions
}

\author{
Ming-liang Chen, ${ }^{1}$ Gao-jian Wu, ${ }^{2}$ Bin-rui Gan, ${ }^{3}$ Wan-hong Jiang, ${ }^{2}$ and Jia-wen Zhou (iD ${ }^{1}$ \\ ${ }^{1}$ State Key Laboratory of Hydraulics and Mountain River Engineering, Sichuan University, Chengdu 610065, China \\ ${ }^{2}$ Sinohydro Bureau 5 Co., Ltd., Power Construction Corporation of China, Chengdu 610066, China \\ ${ }^{3}$ College of Water Resource and Hydropower, Sichuan University, Chengdu 610065, China \\ Correspondence should be addressed to Jia-wen Zhou; jwzhou@scu.edu.cn
}

Received 6 February 2018; Revised 11 April 2018; Accepted 21 May 2018; Published 11 July 2018

Academic Editor: Konstantinos Karamanos

Copyright $\odot 2018$ Ming-liang Chen et al. This is an open access article distributed under the Creative Commons Attribution License, which permits unrestricted use, distribution, and reproduction in any medium, provided the original work is properly cited.

\begin{abstract}
Granular materials in geotechnical engineering is generally considered to be mixtures of clay, sand, and gravel that commonly appear in slopes, valleys, or river beds, and they are especially used for the construction of earth-rock-filled dams. The complexity of the constitution of granular materials leads to the complexity of their properties. Particle size distribution (PSD) has a great influence on the strength, permeability, and compaction behavior of granular materials, and some implicit correlation may exist between the PSD and the compaction properties of granular materials. Field testing and statistical analysis are used to study the physical and compaction properties of granular materials with artificial grading behind the particle size distributions. The statistical properties in PSD of dam granular materials and how the variation of PSD renders statistical constant are revealed. The statistical constants of three types of dam granular materials are 2.459,2.475, and 2.499, respectively, on average. These statistical constants have a positive correlation with dry density and a negative correlation with moisture content. According to this characteristic and little deviation between two different calculation methods (from grading analysis and based on the Weibull distribution), the presentation of the statistical analysis ensures the validity of the Weibull function's description of the granular materials with artificial grading. After fitting the Weibull function to the PSD curve, the relationship between the Weibull parameters and the compaction degree in different soil samples is consistent with that in different types, providing guiding significance for evaluating and selecting dam granular materials.
\end{abstract}

\section{Introduction}

Granular material is widely distributed in nature and is especially relevant in the geotechnical engineering field; it includes landslide deposits, granular soil (fine-grained soil or coarse-grained soil), filling/construction material used for earth-rock dams, and other applications [1-3]. Various granular materials in geotechnical engineering exhibit different material composition, particle size distribution, moisture content, mass density, and other physical/mechanical properties [3-5]. Although the physical/mechanical properties of granular materials are very complicated and difficult to determine, there are potential implicit correlations between the particle size distribution (PSD) and the physical/ mechanical properties of granular materials [6]. Discovering these implicit correlations is very important for understanding the physical/mechanical behavior of granular materials.

The PSD of granular materials is an essential issue for the design of earth-rock-filled dams [7-9]. In practical engineering work, the preparation requires analyzing the range of particle sizes and determining the proportion of grains with various particle sizes. A granular material generally covers a range of particle sizes between $0.001 \mathrm{~mm}$ and $1,000 \mathrm{~mm}$, and it is well known for containing wide-ranging grain composition [10]. Therefore, the scaling distribution for grain composition is a vital index for studying the physical and mechanical properties of soil systems. When the PSD of granular materials is changed, its permeability, deformation, strength, and other properties are altered [11]. During the compaction process of an earth-rock-filled dam, 
TABLE 1: Grain compositions of tested dam granular materials (unit: \%).

\begin{tabular}{|c|c|c|c|c|c|c|c|c|c|c|c|c|c|c|c|}
\hline \multirow{2}{*}{ Type } & \multirow{2}{*}{ Number } & \multicolumn{14}{|c|}{ Particle size (mm) } \\
\hline & & $<0.075$ & $<0.25$ & $<0.5$ & $<1$ & $<2$ & $<5$ & $<10$ & $<20$ & $<40$ & $<60$ & $<80$ & $<100$ & $<200$ & $<300$ \\
\hline \multirow{6}{*}{ A } & $\mathrm{S} 1$ & 4.24 & 10.34 & 13.60 & 13.05 & 14.64 & 27.04 & 10.21 & 6.89 & & & & & & \\
\hline & $\mathrm{S} 2$ & 4.40 & 11.20 & 12.63 & 14.42 & 14.47 & 24.60 & 10.62 & 7.66 & & & & & & \\
\hline & S3 & 4.14 & 14.28 & 12.24 & 14.95 & 13.22 & 25.10 & 12.92 & 3.14 & & & & & & \\
\hline & S4 & 4.76 & 10.27 & 15.34 & 15.60 & 19.31 & 23.10 & 9.02 & 2.60 & & & & & & \\
\hline & S5 & 3.85 & 11.99 & 15.51 & 14.53 & 14.02 & 29.11 & 7.55 & 3.44 & & & & & & \\
\hline & $\ldots$ & $\ldots$ & $\ldots$ & $\ldots$ & $\ldots$ & $\ldots$ & $\ldots$ & $\ldots$ & $\ldots$ & & & & & & \\
\hline \multirow{6}{*}{ B } & $\mathrm{S} 1$ & 2.28 & 9.82 & 6.46 & 8.15 & 12.25 & 17.55 & 15.38 & 19.06 & 9.05 & & & & & \\
\hline & $\mathrm{S} 2$ & 2.89 & 11.87 & 7.06 & 6.84 & 10.36 & 19.81 & 14.03 & 22.00 & 5.14 & & & & & \\
\hline & $\mathrm{S} 3$ & 2.62 & 12.09 & 6.82 & 6.47 & 9.95 & 22.64 & 15.79 & 21.42 & 2.20 & & & & & \\
\hline & $\mathrm{S} 4$ & 2.46 & 9.51 & 5.98 & 7.22 & 9.52 & 20.41 & 19.62 & 18.63 & 6.63 & & & & & \\
\hline & S5 & 2.55 & 11.82 & 6.44 & 8.13 & 11.43 & 18.7 & 14.51 & 18.04 & 8.38 & & & & & \\
\hline & $\ldots$ & $\ldots$ & $\ldots$ & $\ldots$ & $\ldots$ & $\ldots$ & $\ldots$ & $\ldots$ & $\ldots$ & $\ldots$ & & & & & \\
\hline \multirow{6}{*}{$\mathrm{C}$} & $\mathrm{S} 1$ & 2.50 & 3.05 & 3.72 & 4.02 & 4.85 & 6.53 & 13.14 & 12.01 & 5.38 & 8.70 & 6.63 & 5.75 & 16.25 & 7.49 \\
\hline & $\mathrm{S} 2$ & 2.15 & 1.80 & 3.09 & 2.85 & 3.90 & 5.35 & 12.98 & 12.23 & 6.81 & 10.64 & 10.09 & 7.35 & 15.64 & 5.11 \\
\hline & S3 & 1.92 & 1.61 & 2.75 & 2.54 & 3.47 & 4.76 & 11.59 & 13.12 & 8.73 & 9.50 & 7.81 & 9.07 & 16.51 & 6.63 \\
\hline & S4 & 2.52 & 3.05 & 3.43 & 2.68 & 1.88 & 5.86 & 15.47 & 15.85 & 12.08 & 9.41 & 9.67 & 3.89 & 11.19 & 3.01 \\
\hline & S5 & 2.27 & 2.18 & 3.38 & 2.92 & 3.17 & 6.58 & 11.65 & 9.76 & 11.64 & 9.79 & 6.44 & 11.65 & 15.02 & 3.57 \\
\hline & $\ldots$ & $\ldots$ & $\ldots$ & $\ldots$ & $\ldots$ & $\ldots$ & $\ldots$ & $\ldots$ & $\ldots$ & $\ldots$ & $\ldots$ & $\ldots$ & $\ldots$ & $\ldots$ & $\ldots$ \\
\hline
\end{tabular}

the pore reduction between grains is caused by natural settlement and artificial rolling [12]. The compaction properties of granular materials are the key physical indices for the construction of an earth-rock-filled dam.

Previous studies indicated that the phenomenon of compaction dynamics is a slow relaxation influenced by the microscopic characteristics of the grains that may be grain shape, friction, or cohesion [13-15]. Through a large amount of field testing and observation, the macroscopic analysis can provide an opportunity to understand the relationship between PSD and physical/compaction properties $[12,16,17]$. To depict the PSD of soil systems for engineers to intuitively analyze, traditional methods usually use statistics analysis to get a series of characteristic parameters or a cumulative frequency curve [18]. The difficulty in studying a soil system with a complex and irregular clastic rock texture by quantitative characterization is due to the limitations and restrictions of traditional methods where one or two descriptive parameters are hardly suitable and adaptive to the complexity and irregularity of granular materials [19-21].

Since statistical distribution functions were used to describe the grain composition of soil systems [21-23], it has been thought of as a scientific and accurate tool for getting a greater knowledge of the relation between PSD and soil structure [24]. At present, the approach of analyzing the size distribution curve with the statistical analysis is popular for various kinds of soils [25-28]. This paper aims at exploring the physical and compaction properties of the granular materials behind the PSD curve analysis. Three different granular materials are taken as the samples for experiments and analyses, and 50 groups of field tests are carried out for each type of granular materials. The PSDs are analyzed by applying the field testing and statistical analysis methods. Combined with the grading analysis and the PSD functions, the statistical constants of granular materials are analyzed to verify the general applicability of the PSD function for dam filling material and to describe physical characteristics. Then, the parameters in the PSD function are also used to seek the implicit association with the compaction properties of granular materials.

\section{Materials and Methods}

2.1. Sampling and Measuring. The granular materials' samples used in this study are from the filling material for the construction of the Changheba Hydropower Station. The Changheba Hydropower Station is the 10th level hydropower station for cascade development of the Dadu River, and it is located in Kangding County, Sichuan Province, in the Southwest of China [29]. There are more than 10 types of granular materials used for the dam construction, each with different compositions and particle size distributions. Here, three typical types of dam granular materials are used for the field tests and the correlation studies. Table 1 provides some typical grain compositions of the tested dam granular materials. They are the filter dam material \#1 (granular material A, Figure 1(a)), the filter dam material \#3 (granular material B, Figure 1(b)), and the transition dam material (granular material C, Figure 1(c)). 50 groups of related field tests are carried out for each type of granular materials, with the total of 150 groups of field experiments.

The production method of the filter material is processing artificial aggregate by the sand and gravel processing system (contains a large number of fine particles with diameter less than $2.0 \mathrm{~mm}$ ). However, the transition material is the rock material gained by blasting activity in the quarry (most are coarse particles with diameter larger than $2.0 \mathrm{~mm}$ ). During the construction process of filling the dam, field tests are done before rolling compaction on each layer. The procedure takes two dam sections perpendicular to the dam axis as the fixed sections for examining the construction circumstances, and it sets a group every $5.0 \mathrm{~m}$ to measure the PSD of each layer. After compaction by vibration rolling 


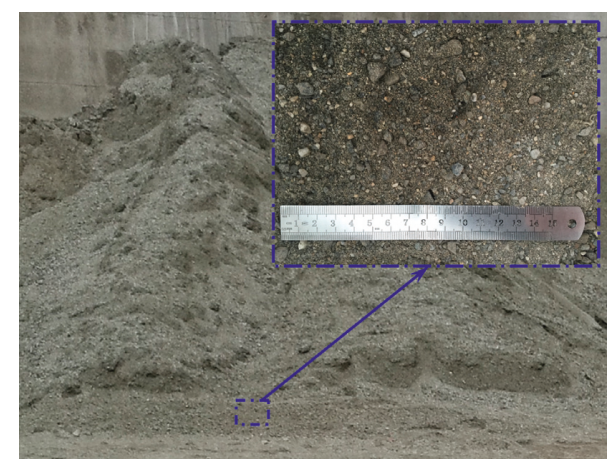

(a)

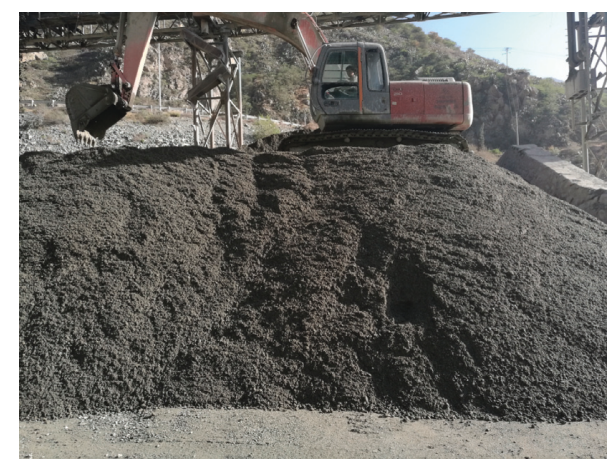

(b)

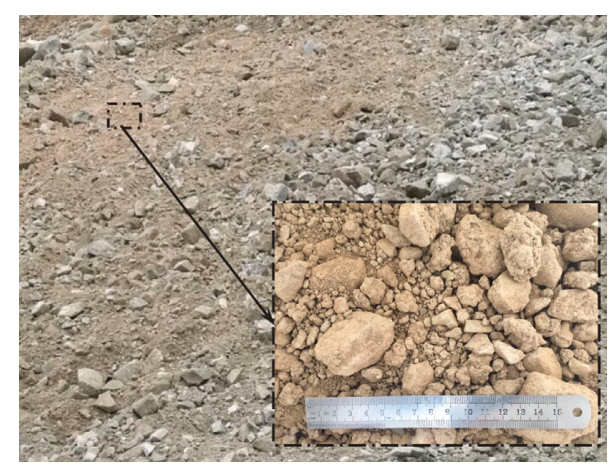

(c)

Figure 1: Photos for the three types of granular materials used in this study: (a) A (filter dam material \#1); (b) B (filter dam material \#3); (c) C (transition dam material).

machinery, the dry density, moisture content, and relative density are measured for each group.

\subsection{Particle Size Distribution (PSD) Characteristics. The PSD} of three granular materials are obtained by the artificial sieving method. Figure 2 shows the particle size distribution characteristics for the three types of tested granular materials. These three types of dam granular materials are produced in two different sites, where the filter dam material is produced at the soil material site and the transition dam material is produced at the rock-fill material site. As shown in Figure 2, there are large differences in particle size range and small differences in material composition (fine-grained soil and coarse rock blocks). The varied particle size distributions result in the different physical and construction properties of the dam granular materials.
2.3. Compaction Degree. The granular materials' compaction degree is a key index for controlling the construction of earth-rock-filled dams, and it has an important effect on the stability and seepage prevention of the dam. After rolling the granular materials to be dense, the grain size distribution reflects the pore size distribution to some extent. Judging the compaction degree of the soil system by porosity neglects the impact of grain shape and particle size distribution. Here, relative density $D_{\mathrm{r}}$ is used as an indicator of compaction. It measures compaction by comparing the porosity when the soil system is in the loosest situation and the densest. It is supposed that relative density is able to comprehensively reflect the impact of particle shape, particle size distribution, and other factors. The equation used to determine the relative density $D_{\mathrm{r}}$ is shown as follows:

$$
D_{\mathrm{r}}=\frac{e_{\max }-e}{e_{\max }-e_{\min }},
$$

where $e$ is the porosity in the natural state of granular materials, $e_{\max }$ is the maximum value of porosity in the loosest state of granular materials, and $e_{\min }$ is the minimum value of porosity in the densest state of granular materials.

The above equation is the theoretical definition of relative density $D_{\mathrm{r}}$. For engineering practice, the relative density is often determined from different dry density test results under different states as follows:

$$
D_{\mathrm{r}}=\frac{\left(\rho_{\mathrm{d}}-\rho_{\mathrm{d} \text { min }}\right) \rho_{\mathrm{d} \text { max }}}{\left(\rho_{\mathrm{d} \text { max }}-\rho_{\mathrm{d} \text { min }}\right) \rho_{\mathrm{d}}},
$$

where $\rho_{\mathrm{d} \text { max }}$ is the maximum dry density in the densest state of granular materials, $\rho_{\mathrm{d} \text { min }}$ is the minimum dry density in the loosest state of granular materials, and $\rho_{\mathrm{d}}$ is the dry density of granular materials after being rolling filled.

\section{Statistical Properties of Granular Materials}

The PSD potential can reflect the complexity and irregularity in structural properties of granular materials and can be used to study the statistical properties between the whole and the parts of granular materials [7]. By using mathematical representation and statistical analysis, one can describe the spatial structure of granular materials through a set of parameters and then try to discuss the correlation between the structural composition and physical properties of the granular materials [20]. Determination of the statistical constant is the core of studying particle size distribution combined with the statistical analysis, and the invariance in the spatial scale for the PSD curve of granular materials provides a scientific basis for depicting the structural composition [30].

3.1. PSD Analysis from Grading Analysis. The grading analysis is a direct method used for the PSD curve of the granular materials. The statistical constant is a mathematical expression of PSD of granular materials by a constant, in which the computational formula can be obtained with some mathematical processing. By using a logarithmic coordinate graph to explain the method and grading analysis, the statistical properties of granular materials can be 


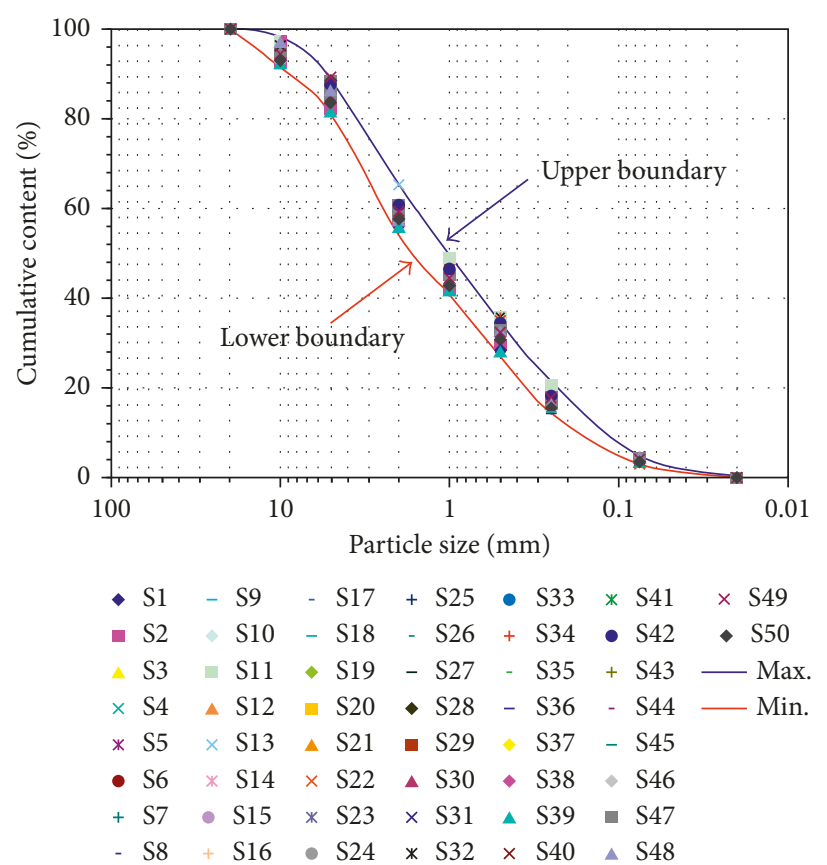

(a)

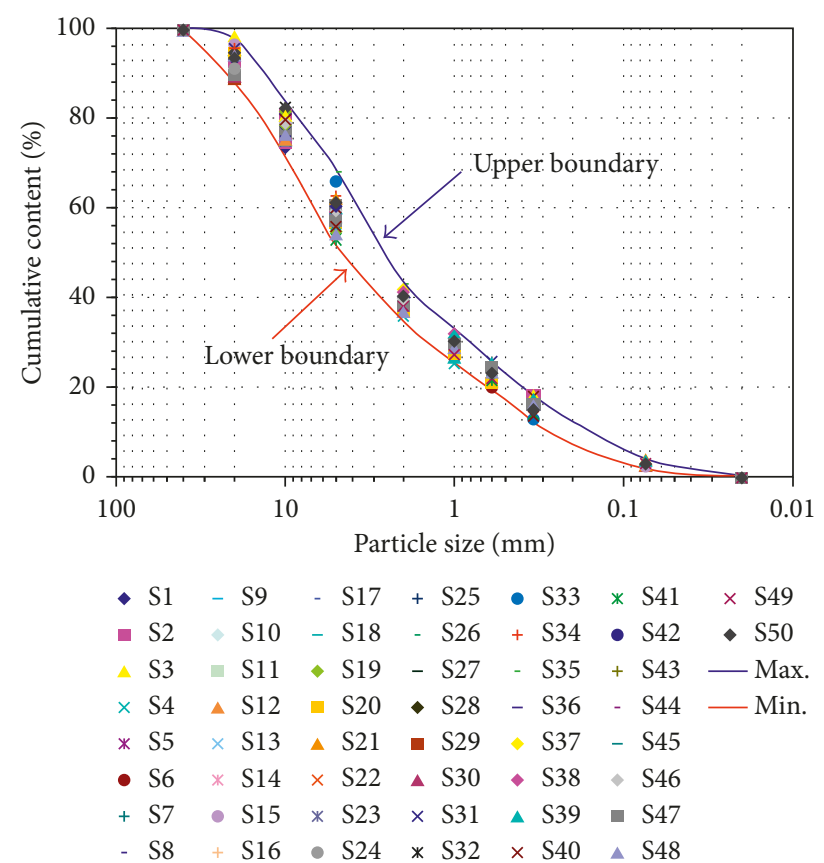

(b)

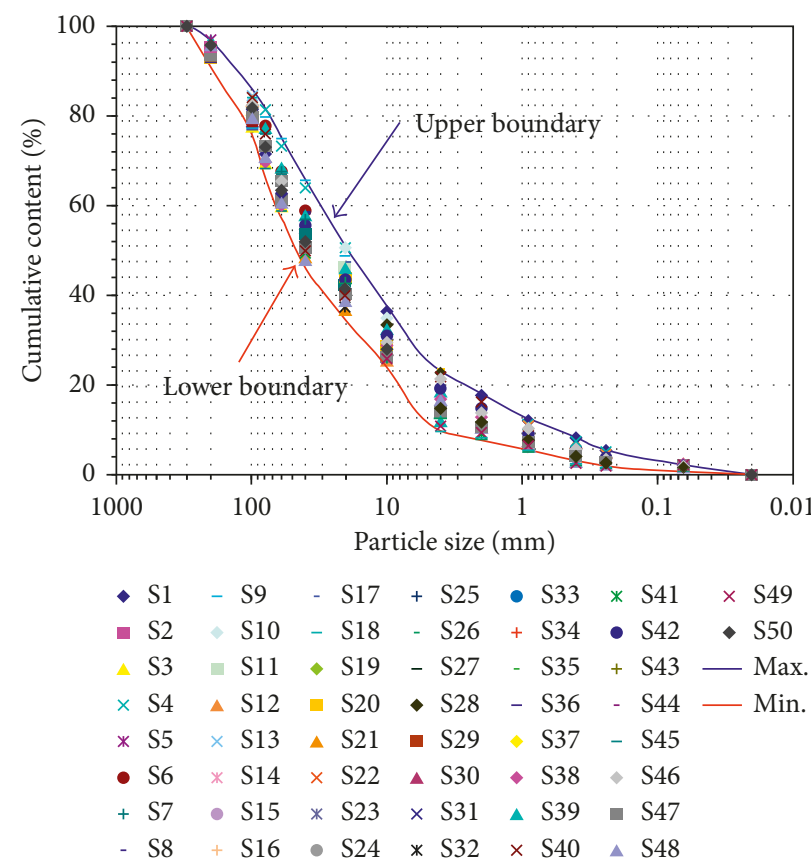

(c)

Figure 2: Particle size distribution characteristics of the tested granular materials: (a) A; (b) B; (c) C.

determined. As shown in Figures 3(a), 4(a), and 5(a), for granular materials with a good grading, the PSD of granular material can be almost viewed as a line. The computational result shows a possibility that PSD of a sample of granular material can be expressed by a constant, related with the gradient of the PSD curve under the log-log coordinate. Usually in engineering, uniformity coefficient $C_{\mathrm{U}}$ and curvature coefficient $C_{C}$ are used as characteristic parameters for evaluating the grain composition of granular materials. As a control parameter can reflect whole performance, the statistical constant has an advantage of simplifying calculation process. However, the validity of statistical constant need be verified for evaluating the grain composition of granular materials. Suppose that $r$ represents the particle size of granular materials and $N(r)$ represents the corresponding cumulative content of the particles with size smaller than $r$. In general, a power law function is suitable for the particle size distribution. According to the definition of statistical constant $D$, the relationship between $r$ and $N(r)$ can be drawn in this way [31]: 


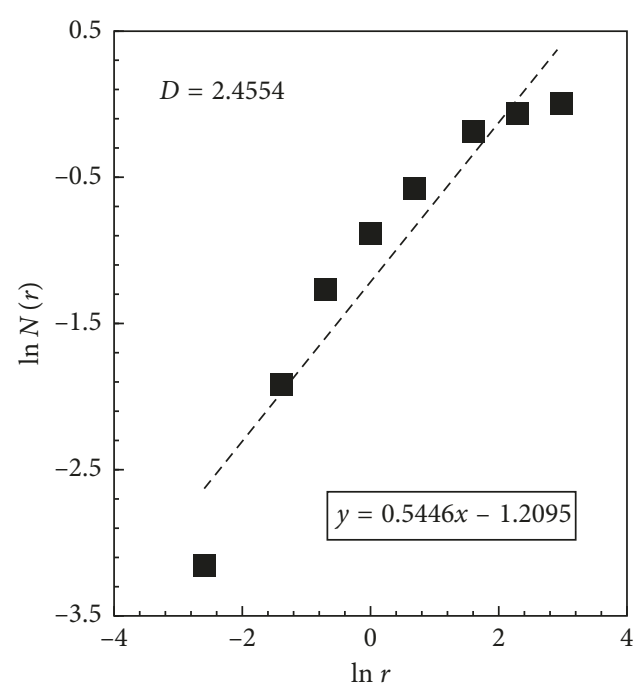

(a)

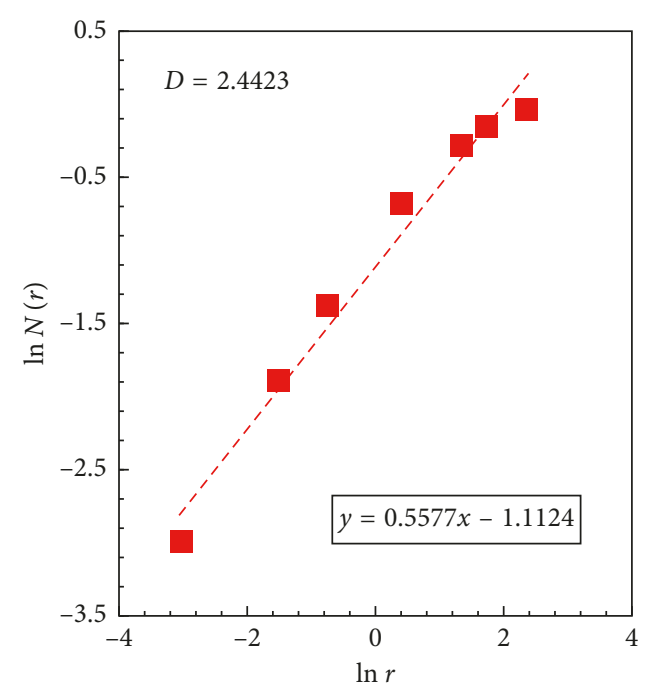

(b)

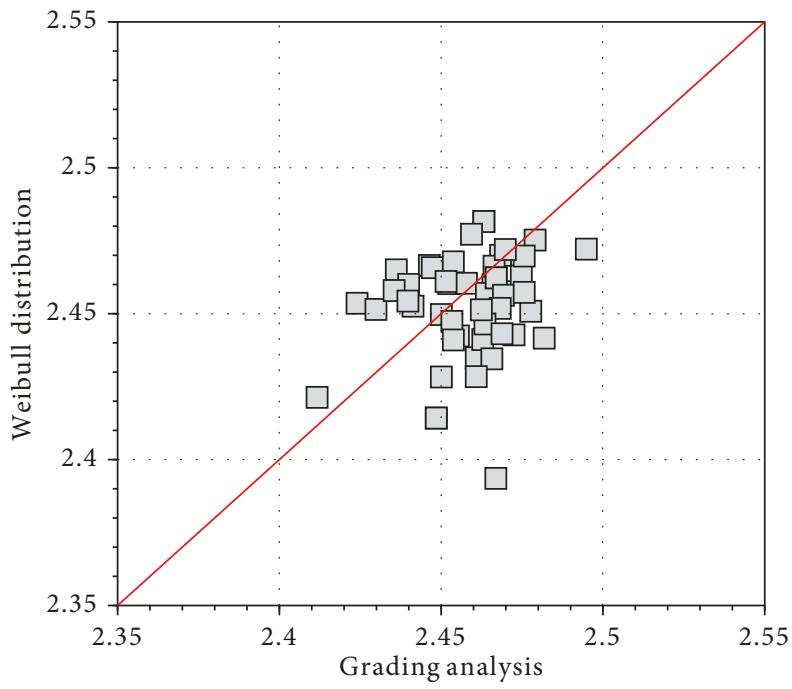

(c)

FIGURE 3: Statistical constant analysis results of dam granular material A and the comparison between different methods: (a) based on the grading analysis (S1); (b) based on the Weibull distribution (S1); (c) difference in the statistical constant results by using different methods ( $r$ represents particle size of granular materials; $N(<r)$ represents the corresponding cumulative content of the grains with the size smaller than $r ; N$ is the total content of all grains).

$$
N(r) \propto r^{-D}
$$

where $D$ is the statistical constant, which is a power law exponent. If one gives a differential operation for (3), it can be expressed as follows:

$$
d N(r) \propto r^{-D-1} d r .
$$

Suppose that $N_{0}$ is the total amount of particles in the granular materials, and the number of grains whose sizes are in $[r, r+d r]$ is

$$
d N=N_{0} d N(r) .
$$

By simultaneously using (4) and (5), the following equation can be obtained:

$$
d N=N_{0} r^{-D-1} d r .
$$

Assume that each particle in the granular materials can be expressed as an equivalent sphere and $k_{r}$ represents the shape factor of the particles, or the proportion coefficient of particle volume and particle size. Then, the particle volume in granular materials can be calculated by the equation $V=k_{r} r^{3}$. If substituted into (6), it can be switched to the following form:

$$
d V=N_{0} k_{r} r^{3} r^{-D-1} d r .
$$

If $V_{0}$ represents the gross volume of the particles in the test sample, it can be obtained from the equation: $d V=V_{0} d N(r)$. Then, (7) can be expressed as follows: 


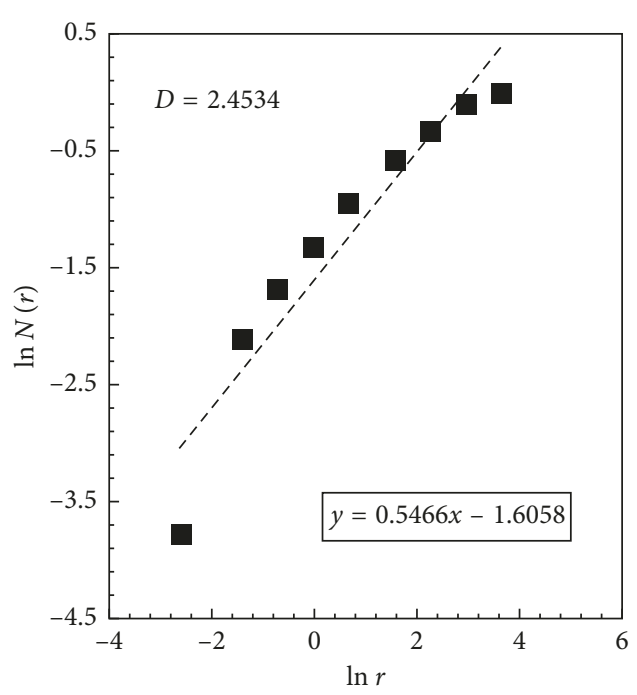

(a)

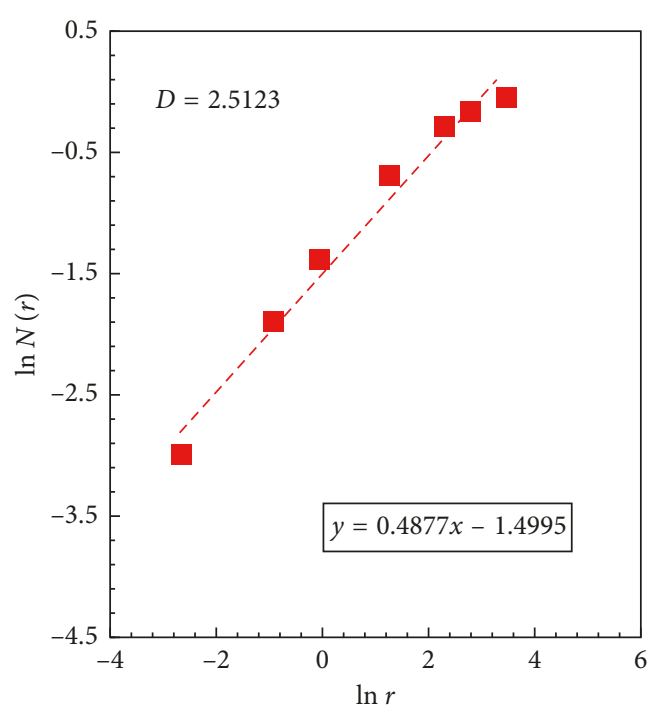

(b)

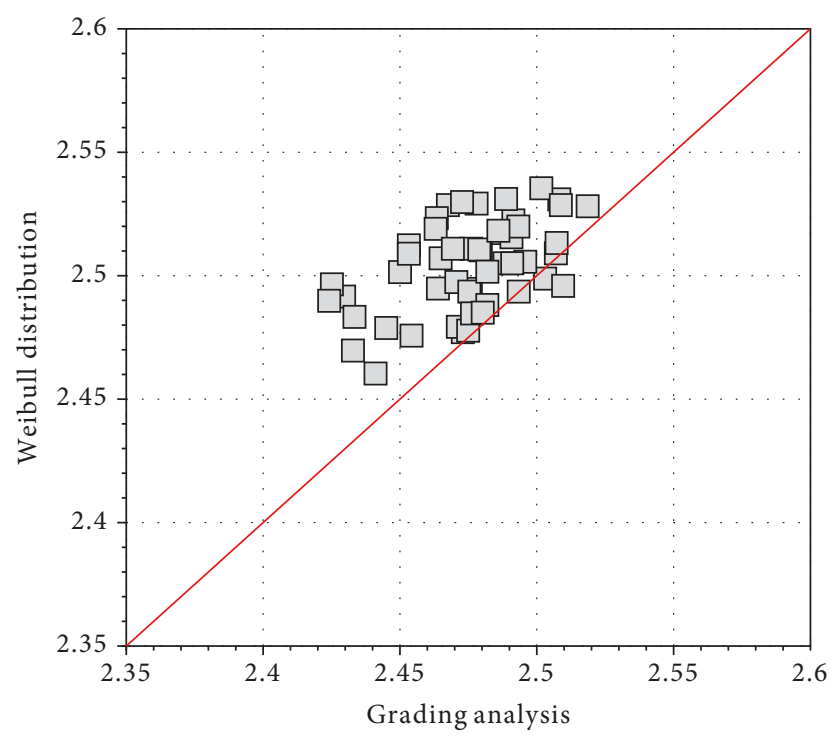

(c)

FIGURE 4: Statistical constant analysis results of dam granular material B and the comparison between different methods: (a) based on the grading analysis (S1); (b) based on the Weibull distribution (S1); (c) the difference in the statistical constant results by using different methods ( $r$ represents particle size of granular materials; $N(<r)$ represents the corresponding cumulative content of the grains with the size smaller than $r ; N$ is the total content of all grains).

$$
d N(r)=\frac{N_{0} k_{r}}{V_{0}} r^{2-D} d r
$$

Integrating (8), then

$$
N(r)=\frac{N_{0} k_{r}}{V_{0}(3-D)} r^{3-D} .
$$

If assuming $N_{0} k_{r} /\left[V_{0}(3-D)\right]$ in (9) is a constant term and $b$ is defined as $b=3-D$, after the logarithmic changes, the relationship between the cumulative content of all the particles whose size is smaller than $r$ can be described as follows:

$$
\ln N(r)=b \ln r+C,
$$

where $\ln (\cdot)$ represents the function of $\log _{e}(\cdot), C$ is a constant, and $b$ is the gradient of the fitting curve between $\ln N(r)$ and $\ln r$. The relationship between the logarithm of the cumulative content of particles with size smaller than $r$ in granular materials and the logarithm of particle size appears to be linear. Based on the above equation, the statistical constant of grains in granular materials can be calculated by the following equation:

$$
D=3-b \text {. }
$$

Equation (11) is the most general form for calculating the statistical constant in the PSD analysis of granular materials; here is a power law exponent. 


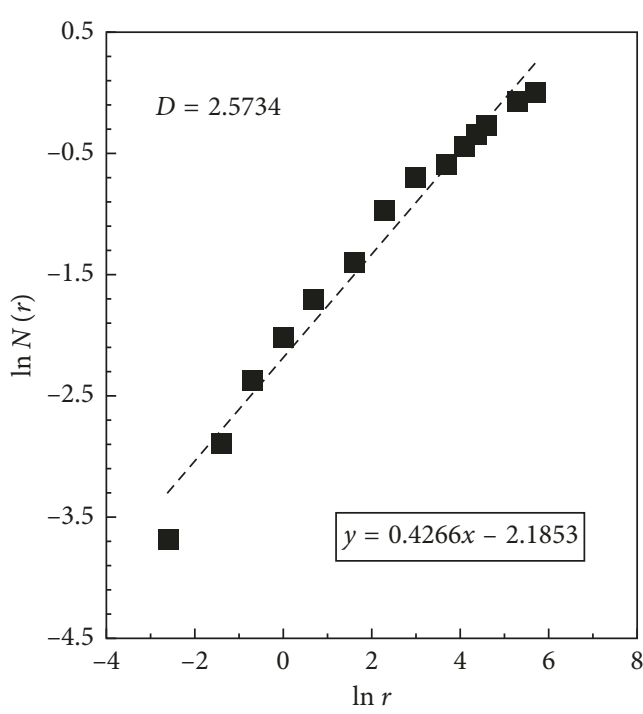

(a)

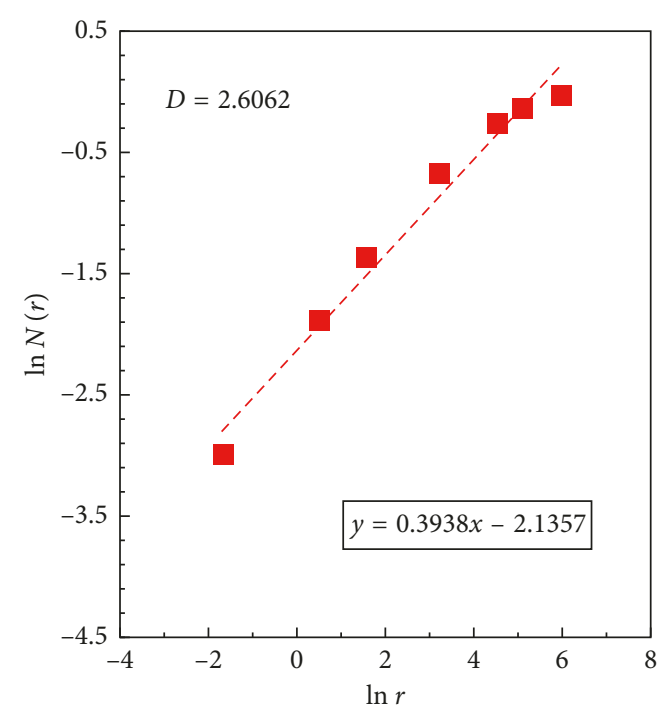

(b)

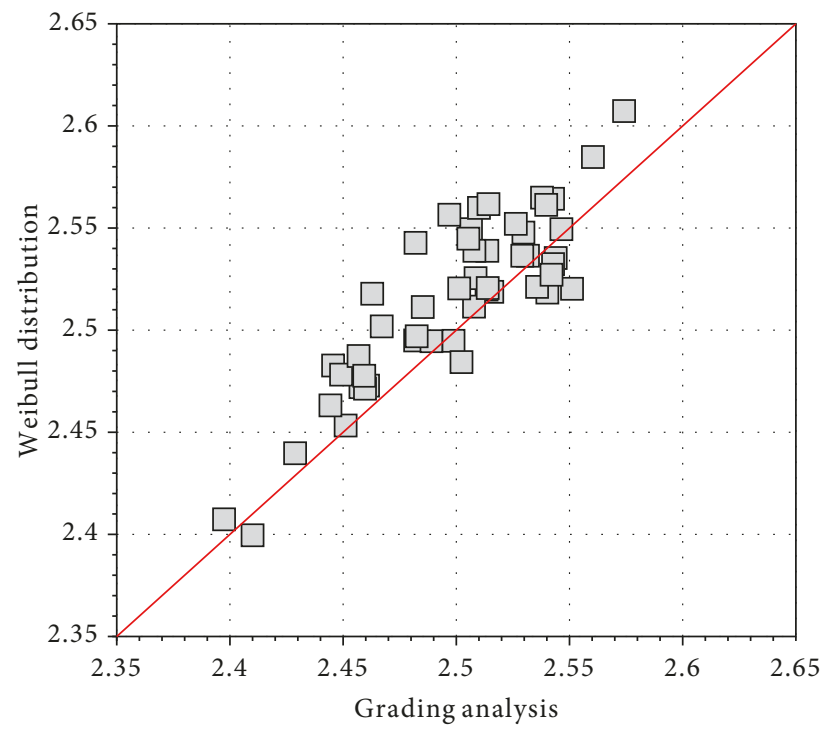

(c)

FIGURE 5: Statistical constant analysis results of dam granular material C and the comparison between different methods: (a) based on the grading analysis (S1); (b) based on the Weibull distribution (S1); (c) the difference in the statistical constant results by using different methods ( $r$ represents particle size of granular materials; $N(<r)$ represents the corresponding cumulative content of the grains with the size smaller than $r ; \mathrm{N}$ is the total content of all grains).

3.2. Statistical Analysis Based on the Weibull Distribution. Frequently used mathematical representations for describing the PSD of granular materials are the Rosin-Rammler distribution function [32] and Weibull distribution function [33-35]. The particle groups of natural granular materials possibly exist with discontinuous distributions, due to complex geological formation histories, and may introduce some errors when using the mathematical distribution functions to analyze the PSD of natural granular materials. However, for the artificially prepared granular materials (which can be seen as having the same properties as natural granular materials), due to the requirements of stability and seepage prevention, the continuity of particle groups is often better than that for the natural granular materials. Therefore, the mathematical distribution functions can better describe granular materials with artificial grading for the construction of earth-rock-filled dams.

Here, a two-parameter Weibull distribution with a size parameter $r_{0}$ and a shape parameter $b$ is used to describe PSD of dam granular materials. According to the definition of two-parameter Weibull distribution, size parameter and shape parameter are strongly related with the shape of the PSD curve. The size parameter represents the average size of particles in a sample of granular materials, and the shape parameter reflects the distributed wide range of particle size. By using the Weibull distribution, the Weibull parameters have an advantage of directly reflecting statistical characteristics of PSD of granular materials than the 
uniformity coefficient and curvature coefficient. The formula of the Weibull distribution is shown as follows:

$$
\frac{M(<r)}{M}=1-\exp \left[-\left(\frac{r}{r_{0}}\right)^{b}\right],
$$

where $M(<r)$ is the cumulative content of all particles whose size is smaller than $r$ and $M$ is the total volume of all particles.

By applying the Taylor progression for (12), a concise equation can be obtained as follows:

$$
\frac{M(<r)}{M}=\left(\frac{r}{r_{0}}\right)^{b} \text {. }
$$

Then, by adopting a differential operation for (13), a simple power equation can be expressed as follows:

$$
d M(<r)=r^{b-1} d r .
$$

The volume of the whole particles in granular materials can be calculated by $V=k_{r} r^{3}$, and $\rho$ is a constant defined as the particle density. Then, the mass of the whole grains can be given by $M=\rho k_{r} r^{3}$. Assuming each particle in the granular materials can be represented as an equivalent sphere and applying $M=\rho k_{r} r^{3}$ to (7), the following equation can be obtained:

$$
d M=\rho d V=N_{0} \rho k_{r} r^{3} r^{-D-1} d r
$$

If $M_{0}$ represents the gross mass of the granular materials, it can be obtained from this equation: $d M=M_{0} d N(r)$. Then, (15) can be expressed as follows:

$$
d N(r)=\frac{N_{0} \rho k_{r} r^{2-D}}{M_{0}} d r .
$$

Integrating (16),

$$
N(r)=\frac{N_{0} \rho k_{r}}{M_{0}(3-D)} r^{3-D}
$$

Equation (17) has the same form as (9), so the same treatment method for (17) can be used to determine the statistical constant of the PSD for granular materials with the Weibull distribution. Although there are some differences in the statistical constant results between using grading analyses or the Weibull distribution, the difference is very small if the continuity of gradation in the granular materials is high. The difference in the statistical constant between the grading analysis and the Weibull distribution can reflect some properties of the PSD, especially in the continuity of gradation for granular materials.

\subsection{Relationship between PSD and Statistical Constant.} The physical properties of granular materials have a significantly positive correlation with the statistical constant (Figures 3-5), which further means that the statistical constant is qualified to become an evaluation indicator of the soil character. Based on the Weibull distribution and the gradation analysis, respectively, we calculate the statistical constant. Then, after comparing the results, the
TABle 2: Computational results for the statistical constant of different dam granular materials (all of the field test samples).

\begin{tabular}{lcccc}
\hline Statistical constant, $D$ & $\begin{array}{c}\text { Granular } \\
\text { material A }\end{array}$ & $\begin{array}{c}\text { Granular } \\
\text { material B }\end{array}$ & $\begin{array}{c}\text { Granular } \\
\text { material C }\end{array}$ \\
\hline \multirow{4}{*}{ Grading } & Maximum & 2.495 & 2.519 & 2.573 \\
analysis & Minimum & 2.412 & 2.424 & 2.397 \\
& Average & 2.459 & 2.475 & 2.499 \\
& Standard & 0.016 & 0.023 & 0.040 \\
\hline \multirow{4}{*}{ Weibull } & deviation & & & \\
distribution & Maximum & 2.482 & 2.535 & 2.606 \\
& Minimum & 2.394 & 2.460 & 2.399 \\
& Average & 2.453 & 2.504 & 2.515 \\
& Standard & 0.018 & 0.018 & 0.042 \\
\hline
\end{tabular}

difference value verifies the general applicability of the Weibull distribution to the grain composition of granular materials.

The diversity of lithologic compositions, physical properties, and grain size distributions results in statistical constant differences [7, 9, 16]. Table 2 summarizes the computational results for the statistical constant of different tested granular materials (all of the field test samples). As shown in Figures 3(c), 4(c), and 5(c), for all three types of granular materials, there is a good correlation for the statistical constant calculated based on the Weibull distribution and/or grading analysis, and the error is within the range from $-3 \%$ to $3 \%$. Although grain composition with artificial design violates the basic rule of particle aggregation in natural conditions to a certain degree, the calculation results indicate that the Weibull function has applicability in describing the PSD. The general validity of reflecting the PSD characteristics becomes the foundation for further exploring the question of whether PSD has a definite mathematical link with the physical and mechanical properties of dam granular materials.

Although the error of the statistical constant determined by the grading analysis and the Weibull distribution is small, there is an erratic fluctuation phenomenon in these two different methods (Figures 6(a) and 6(b)). The erratic fluctuation in statistical constants of dam granular material $\mathrm{C}$ is the largest and that of dam granular material $\mathrm{A}$ is the smallest. For example, the minimum statistical constant of granular material $\mathrm{C}$ is even lower than that of granular material $\mathrm{A}$, although the average value of statistical constant for granular material $\mathrm{C}$ is larger than that of granular material A. For dam granular materials A and C, the fluctuation degree of the statistical constant from the grading analysis is higher than that from the Weibull distribution. However, the fluctuation degree of the statistical constant for dam granular material B from the grading analysis is lower than that from the Weibull distribution. If making an analysis according to the amplitude of fluctuations, the particle size range of granular materials influences the fluctuation degree of the statistical constant, as is proven to be true by the standard deviations of all the granular material samples of each type. Therefore, understanding how the behavior of PSD curves leads to the variation of the statistical 


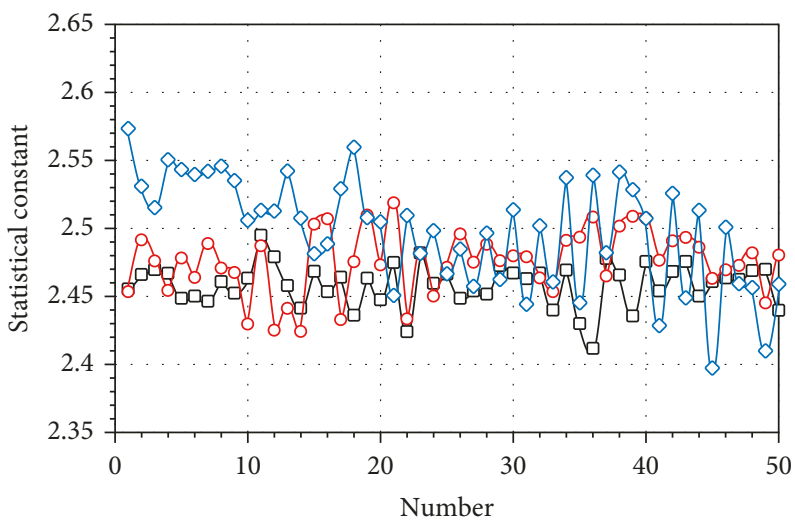

- - Granular material A

-o- Granular material B

$\multimap$ Granular material C

(a)

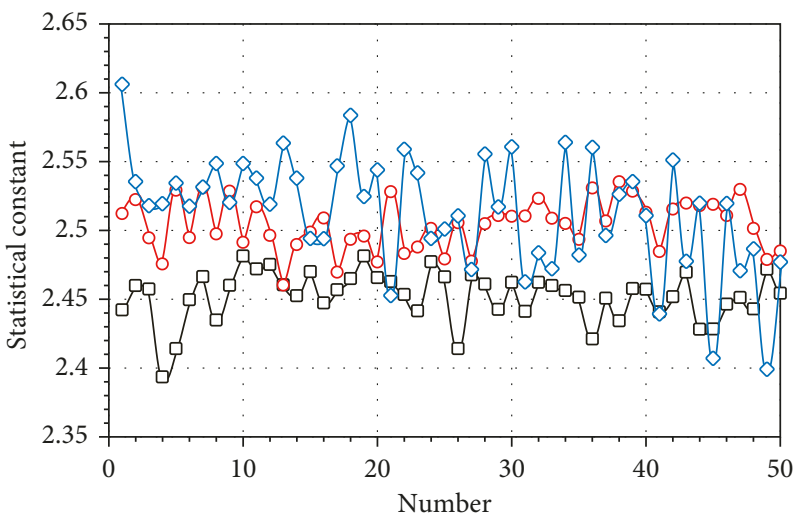

- - Granular material A

- - Granular material B

$\multimap$ Granular material C

(b)

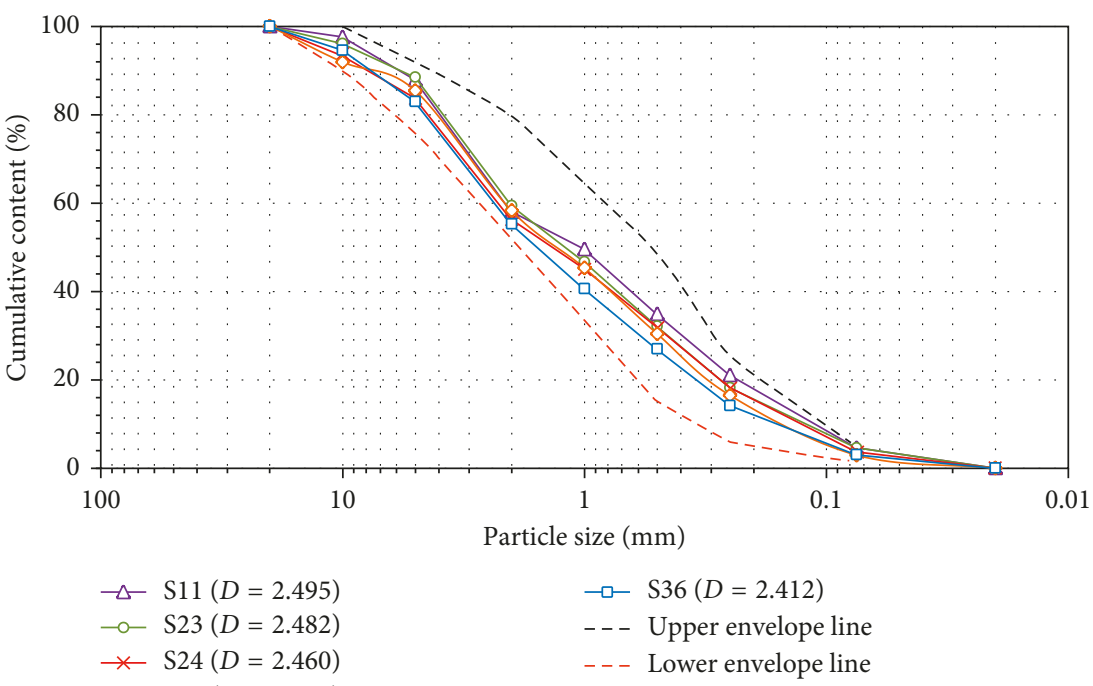

(c)

FIGURE 6: Continued. 


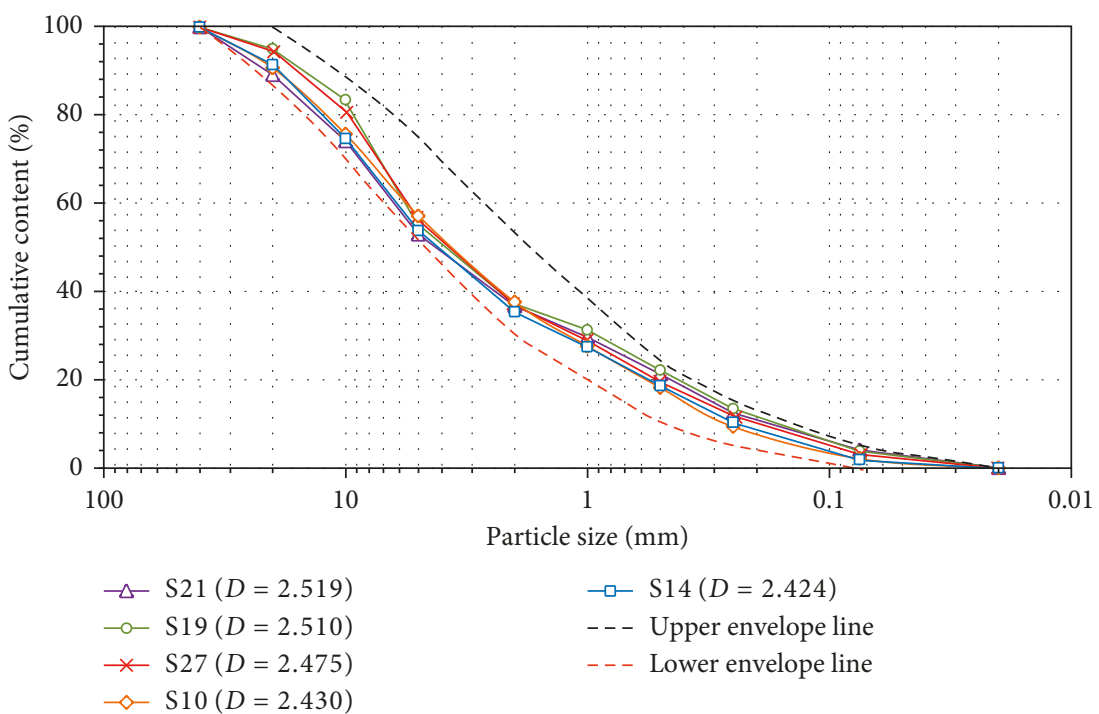

(d)

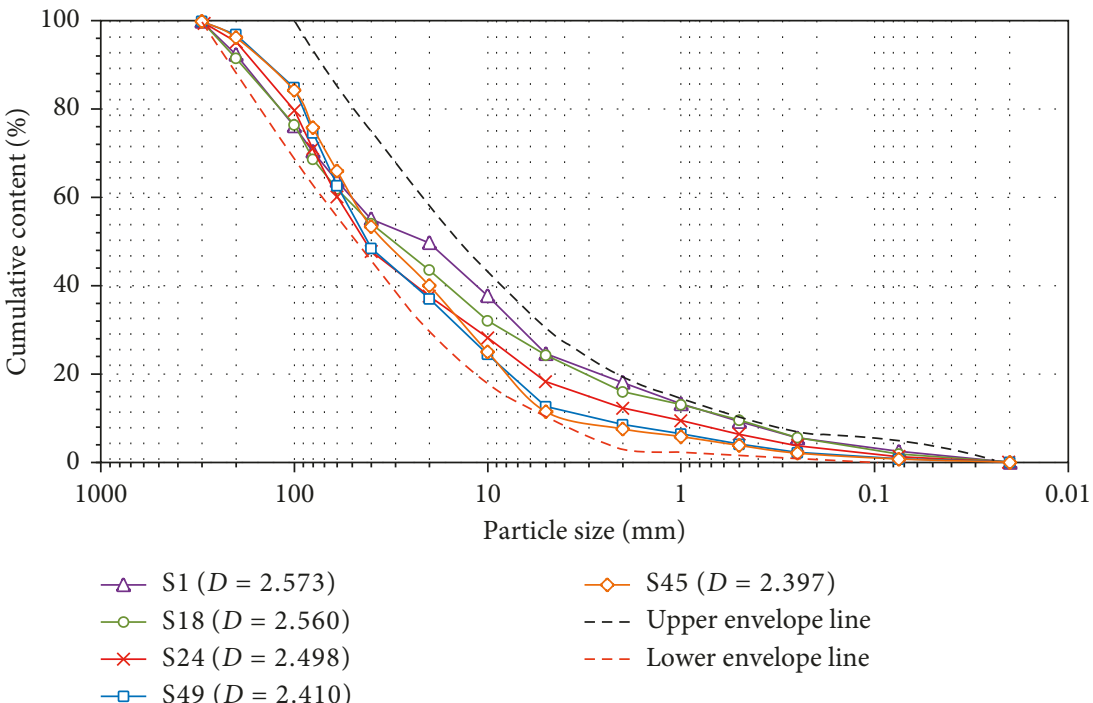

(e)

FIGURE 6: Statistical constant analysis results of different dam granular materials: (a) determined by the grading analysis; (b) determined by the Weibull distribution; typical PSD curve and the statistical constant for selected samples of granular materials (c) A, (d) B, and (e) C.

constant has vital importance for analyzing the physical characteristics of granular materials.

According to the design requirements for dam granular materials, the curves of PSD have been limited by the envelope lines (including the upper and lower envelope lines for different dam granular materials) for satisfying the requisite seepage and stability conditions (Figures 6(c)-6(e)). As shown in Figure 6 and Table 1, the samples of granular materials used in field tests are considered to be soils with continuous uniform grading and both have adequate compaction results for further construction. When the grain composition varies within the limited range restricted by the envelope lines, the statistical constant also varies within a certain range. For granular material $\mathrm{A}$, the statistical constant is increasing where the particle size distribution curve is closer to the upper envelope line and decreasing where the distribution curve is closer to the lower envelope line (Figure 6(c)). The analysis results indicate that the rising content of the particle group with size less than $5 \mathrm{~mm}$ and the dropping content of the particle group with size more than $5 \mathrm{~mm}$ result in the increase of the statistical constant. For granular material B, the PSD is found to have a similar developing principle and distribution regularity compared to granular material A (Figure 6(d)). During the preparation and production of granular materials with a relatively small particle size range, the content of the fine particle group is a vital matter owing to the fact that an inappropriate setting can cause the statistical constant to be far away from the average level. For granular material C, the PSD with higher statistical constant has a characteristic where its bottom part is closer to the upper envelope line and its top part is nearer to the lower envelop line (Figure 6(e)). Granular material C is supposed to have a wide range of particle size. The descent of the intermediate particle group whose size is between 
$5 \mathrm{~mm}$ and $40 \mathrm{~mm}$ can lead to the growth of statistical constant because the PSD has a good correlation with the statistical constant. Therefore, if the analysis is combined with Figure 2 and Table 2, it can be concluded that the particle size range and the uniformity of the grading distribution affect the physical properties and can further be represented by the statistical constant.

When studying PSD of granular materials, the practice normally derives characteristic coefficients to describe grain composition. The uniformity coefficient $C_{U}$ reflects the uniformity of the grading distribution in granular materials. The curvature coefficient $C_{\mathrm{C}}$ describes the entire morphology about the gradation accumulation curve of grain composition. However, the statistical constant $D$ can be used to predict the characteristic value of distribution curves as a comprehensive indicator reflecting the structure of soil samples. According to the different sections in the particle size distribution curve, the varied gradient $b$ of the curve can be obtained as follows (here three typical characteristic values are used):

$$
\begin{aligned}
& b_{1}=\frac{\lg 30-\lg 10}{\lg d_{30}-\lg d_{10}}=\frac{\lg 3}{\lg \left(d_{30} / d_{10}\right)}, \\
& b_{2}=\frac{\lg 60-\lg 10}{\lg d_{60}-\lg d_{10}}=\frac{\lg 6}{\lg \left(d_{60} / d_{10}\right)}, \\
& b_{3}=\frac{\lg 60-\lg 30}{\lg d_{60}-\lg d_{30}}=\frac{\lg 2}{\lg \left(d_{60} / d_{30}\right)} .
\end{aligned}
$$

Assuming the PSD curve after the logarithmic operation is a linear function, which means that $b_{1}=b_{2}=b_{3}=b$, then the following equations can be obtained:

$$
\begin{aligned}
& \frac{d_{30}}{d_{10}}=3^{1 / b}=3^{1 /(3-D)}, \\
& \frac{d_{60}}{d_{10}}=6^{1 / b}=6^{1 /(3-D)}, \\
& \frac{d_{60}}{d_{30}}=2^{1 / b}=2^{1 /(3-D)} .
\end{aligned}
$$

On the basis of the definition of the grading index, the relationships between statistical constant and uniformity coefficient and curvature coefficient can be determined as follows:

$$
\begin{aligned}
& C_{\mathrm{U}}=\frac{d_{60}}{d_{10}}=6^{1 /(3-D)}, \\
& C_{\mathrm{C}}=\frac{d_{30}^{2}}{d_{10} d_{60}}=1.5^{1 /(3-D)} .
\end{aligned}
$$

However, if we observe Figures 3-5, it will be found that the curve $\ln N(r)=b \ln r+C$ incompletely coincides with the grading distribution curve. The curve $C_{\mathrm{C}}=C_{\mathrm{U}}^{\ln 1.5 / \ln 6}=$ $C_{\mathrm{U}}^{0.2263}$ can be gained by switching (20) and (21). Taking granular material $\mathrm{C}$ as an example, there is also a fitting curve $C_{\mathrm{C}}=0.2501 C_{\mathrm{U}}^{0.4945}$ as a result of the characteristic coefficients $\left(C_{\mathrm{C}}\right.$ and $\left.C_{\mathrm{U}}\right)$ calculated by the linear interpolation method (Figure $7(\mathrm{~b})$ ). The theoretical curve $C_{\mathrm{C}}=C_{\mathrm{U}}^{0.2263}$ calculated with the statistical constant is the same type function as the fitting curve $C_{\mathrm{C}}=0.2501 C_{\mathrm{U}}^{0.4945}$. Although deviation exists in the two curves, it states that the method based on the statistical constant is feasible. Compared to the linear interpolation method, it is much more convenient and has a more stable range of calculated results. The characteristic coefficients are made from the analysis of the part distribution character. The definition of the characteristic coefficients on the basis of several characteristic particle sizes of a certain distribution curve is unable to present the integral distribution of grain composition. Because of its lack of integrality and adaptability, the accuracy of the definition is an issue in itself that needs to be investigated. However, the statistical constant is considered to be an indicator with integrality. Thinking of it in reverse, the statistical constant can be used as an engineering indicator to evaluate whether artificial aggregate is in good condition.

When comparing the results calculated from two different methods, the uniformity coefficient results are in basic agreement (Figure $7(\mathrm{a})$ ). The assumption of the method based on the statistical constant is that the granular material is supposed to have a good degree of uniformity for grading distribution, which is the following condition: $b_{1}=b_{2}=$ $b_{3}=b$. It leads to keeping the curvature coefficient values between 1 and 3 (Figures 7(d) and 7(f)). The value of the uniformity coefficient is obtained from the ratio of two special particle sizes $\left(d_{60}\right.$ and $\left.d_{10}\right)$. The linear interpolation calculation method is, supposedly, commonly used with negligible error. As shown in Figures 3(a), 4(a), and 5(a), the uniformity of the particle group distribution of granular material $\mathrm{C}$ is better than granular materials $\mathrm{A}$ and $\mathrm{B}$, which can be stated as the deviation of the calculated characteristic coefficient values for granular material $\mathrm{C}$ is lower than that for granular materials A and B. Therefore, for granular material $\mathrm{C}$, the calculated value based on the statistical constant is more accurate. As shown in Figure 7(a), the uniformity coefficient based on the statistical constant is universally lower than the linear interpolation method for granular material $\mathrm{C}$, and there are contrary results for granular materials $\mathrm{A}$ and $\mathrm{B}$. When $d_{10}$ is smaller than $1 \mathrm{~mm}$ and $d_{60}$ is higher than $20 \mathrm{~mm}$, just a little deviation may result in the calculated uniformity coefficient values getting much larger (Figures 7(a) and 7(e)). The calculation results indicate that the computational method based on the statistical constant can better control the results' range.

\section{Physical and Compaction Properties behind the PSD}

The compaction degree is a major construction control index for detecting the quality of core rock-fill dam. During the construction process, the factors affecting the compaction properties are complex and numerous, including grain composition, aggregate shape, moisture content, rolling technology, and compaction power. However, it is difficult to analyze each factor and understand its mechanism. If preparing the granular materials according to the traditional norms and requirements, the actual compaction degree will 


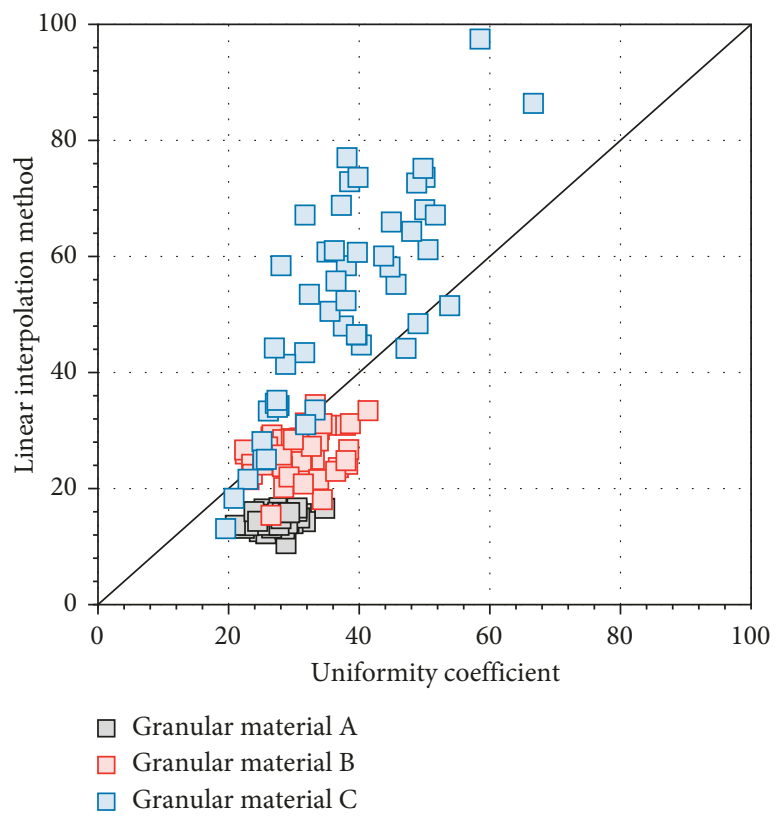

(a)

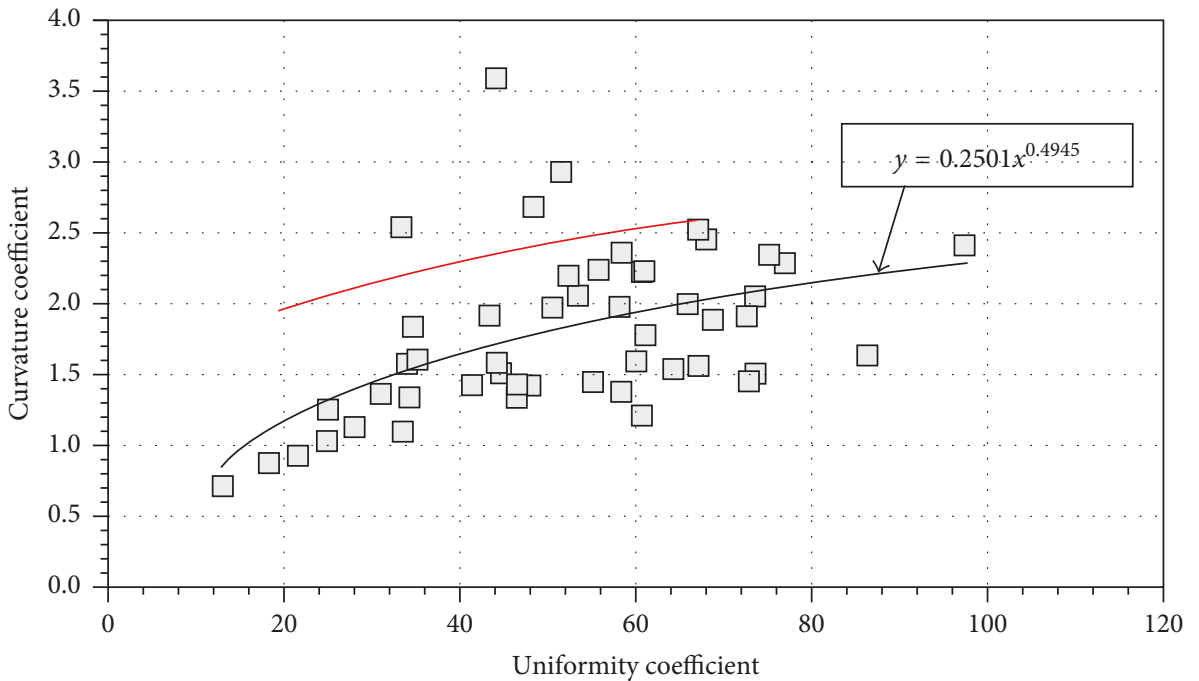

Based on statistical constant

$\square \quad$ Linear interpolation method

_ Fitting curve (LIM)

(b)

FIgURE 7: Continued. 


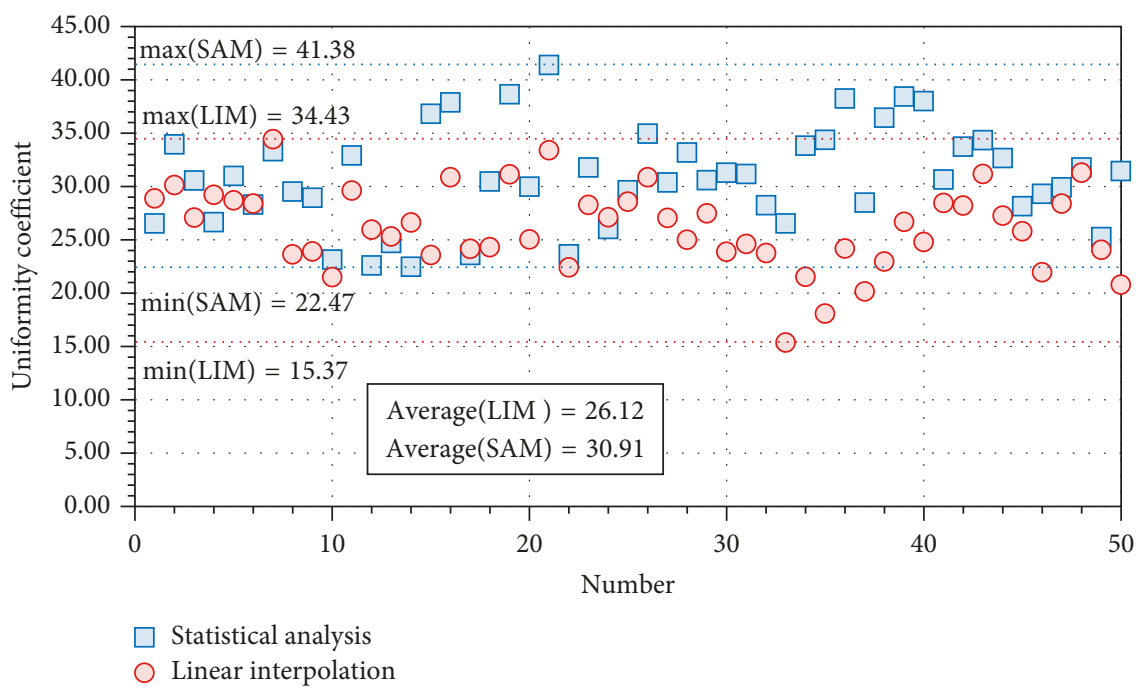

(c)

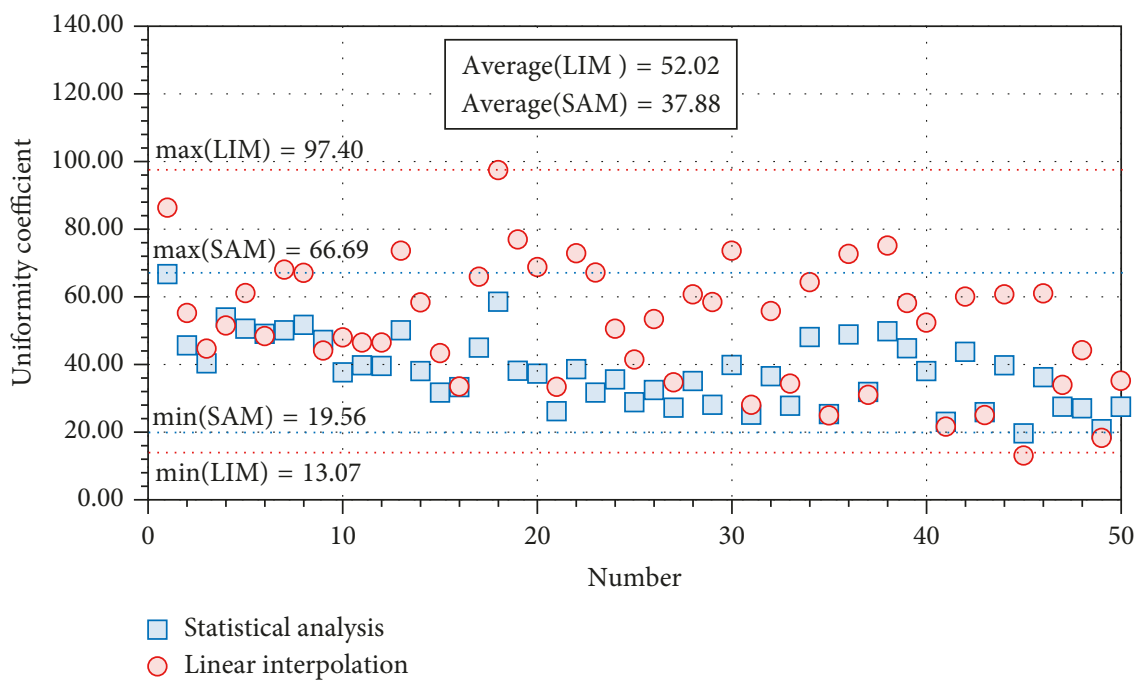

(d)

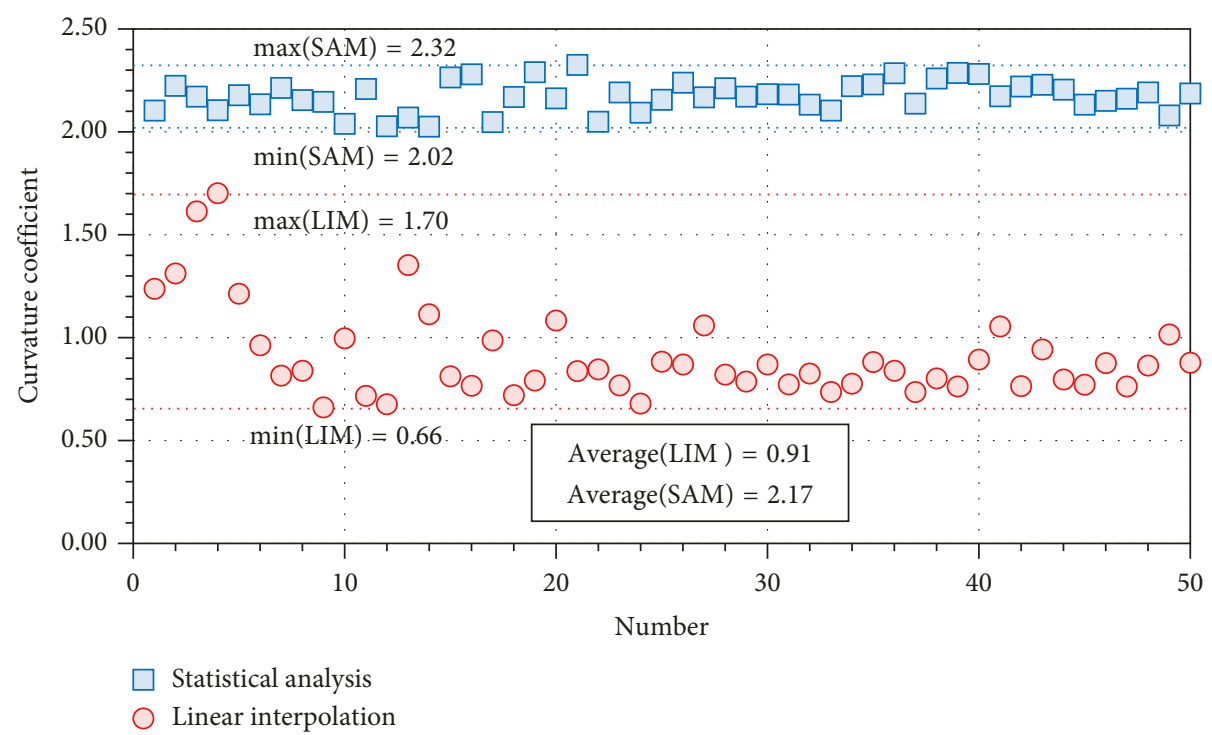

(e)

Figure 7: Continued. 


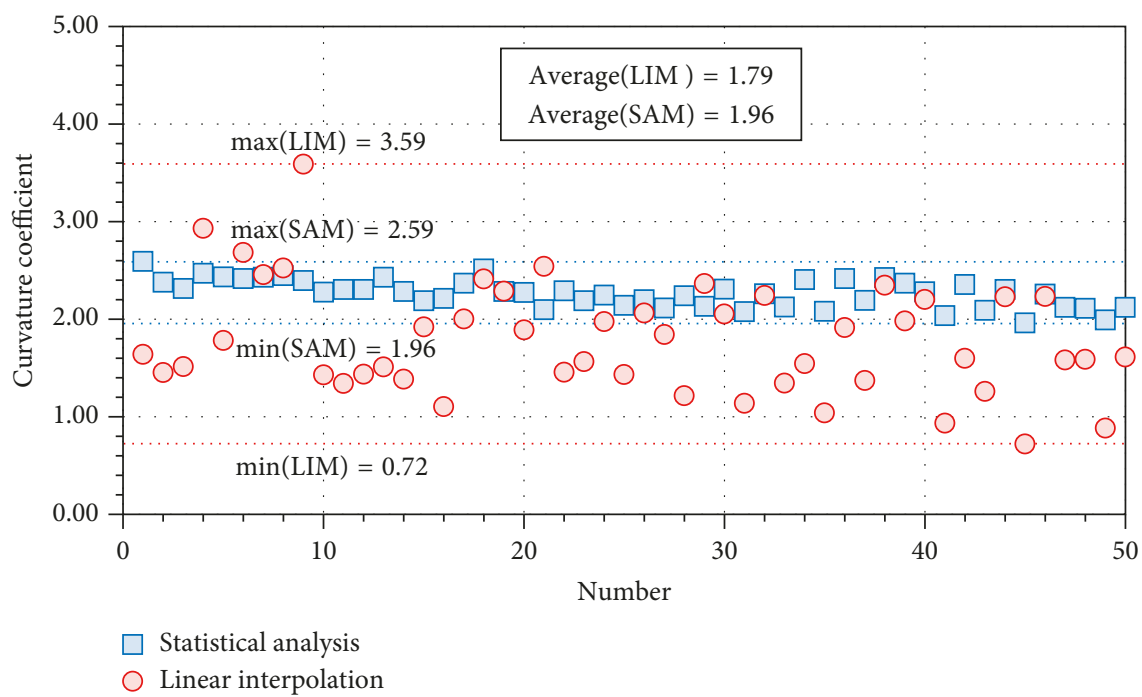

(f)

FIGURE 7: Characteristic values of the distribution curve of different granular materials: (a) correlation of the uniformity coefficient for PSD curves from the linear interpolation method and based on the statistical constant; (b) relationship between the uniformity coefficient and the curvature coefficient for PSD curves; (c) uniformity coefficient results for granular material B; (d) curvature coefficient results for granular material B; (e) uniformity coefficient results for granular material C; (f) curvature coefficient results for granular material C (LIM represents the linear interpolation method; $\min (\mathrm{LIM})$ and $\max (\mathrm{LIM})$ represent the minimum and the maximum uniformity coefficients of the PSD curve by using the linear interpolation method, resp.; $\min (\mathrm{SAM})$ and $\max (\mathrm{SAM})$ represent the minimum and the maximum uniformity coefficients of the PSD curve by using the statistical analysis method, resp.; average(LIM) and average(SAM) represent the average values for the uniformity coefficients of the PSD curve by using the linear interpolation method and statistical analysis method, resp.).

have difficulty in reaching the engineering standard. Studying the compaction properties only by particle size is short of preciseness and accuracy. However, based on the Weibull distribution, the size and shape parameters are beneficial for understanding how to impact the compaction process in practice. This work focuses on the potential mathematical relation between the Weibull parameters and compacting properties, which can testify as to whether the Weibull distribution has the ability to be taken as a supplement to construction specifications for evaluating and selecting dam granular materials.

4.1. The Relationship between the Statistical Constant and Physical Properties. Granular materials in a relatively loose state have more pores than relatively tight states making it possible to hold more water. Exploring the relationship between the statistical parameters and physical properties can validate the effectiveness of the statistical constant in describing the spatial structure of granular materials. As shown in Figure 8(c) and Table 3, the statistical constant has a positive correlation with dry density and a negative correlation with moisture content. The calculated result is in accord with the recent research for the link between the statistical parameters, water, and physical properties [3638]. As a result, the good correlation between the statistical constant and physical properties indicates that the statistical constant can quantifiably integrate the structure of dam granular materials. However, the correlation between the statistical parameters and physical properties has obvious limitations. For certain granular materials, the variation of the statistical constant has no possible effect on physical properties. As shown in Figures 8(a) and 8(b), moisture content and dry density have no obvious change associated with the statistical constant and stay within a reasonable range. However, the correlation can be established among different kinds of granular materials. These characteristics illustrate that the point is aimed specifically at the sorting of granular materials whose statistical constant is a character parameter for the spatial feature. In other words, the statistical constant is only suitable for representing the integral level of physical and compaction properties or PSD.

Therefore, we cannot choose the statistical constant as the character parameter for evaluating the compaction properties of granular materials owing to the lack of the validity specific to the same sort. However, every single dam granular sample has a specific set of Weibull parameters to match. Meanwhile, this set of Weibull parameters has the ability to show different performances compared to not only the granular material samples of a sort but those belonging to other sorts (Table 4). Based on the statistical analyses, the paper has proven that the Weibull distribution is generally applicable for describing granular materials. As abovementioned, some latent correlation must exist between the variation of the Weibull parameters and the alteration of granular materials behavior and it can be explored.

4.2. The Relationship between the Weibull Parameters and Compaction Properties. The spatial distribution after rolling compaction of granular materials with a wide particle size range depends on a number of factors besides the size 


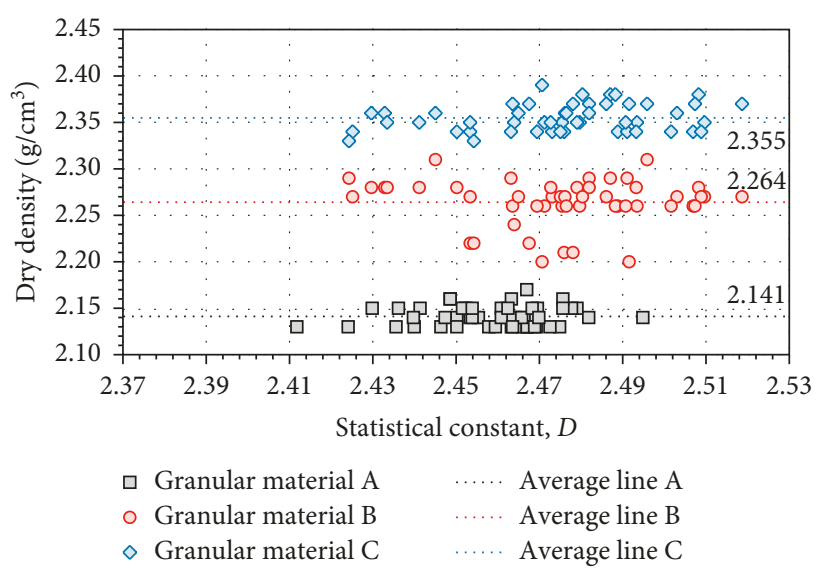

(a)

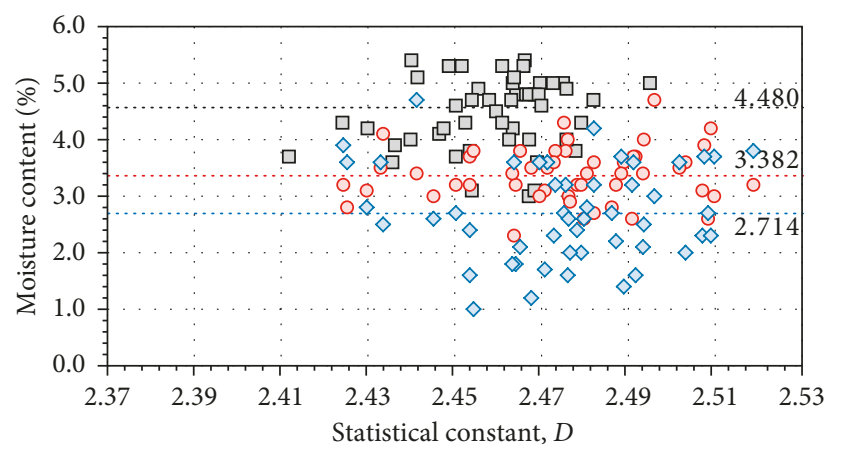

口 Granular material A

- Granular material B

$\diamond$ Granular material C

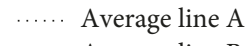

Average line B

Average line $\mathrm{C}$

(b)

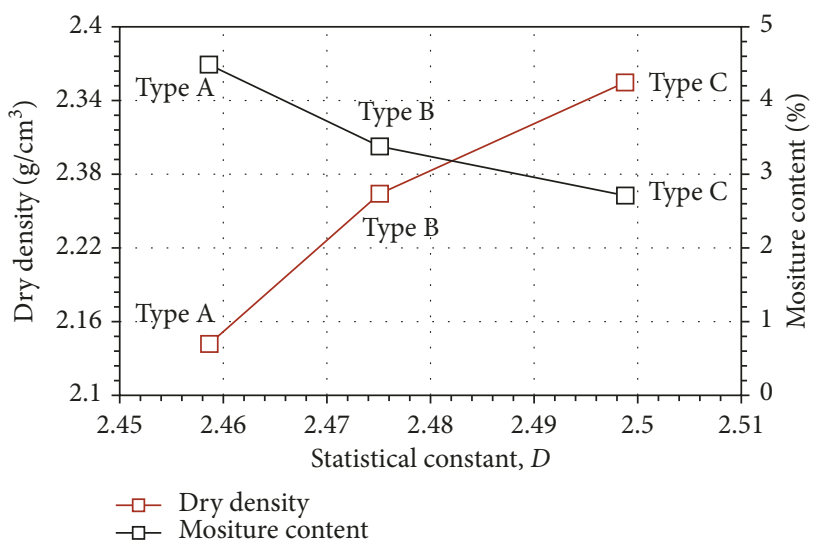

(c)

FIgURE 8: Relationship of the physical properties of granular materials and the statistical constant (all of the 50 groups for each type of granular materials are used): (a) the relationship behind the types; (b) the graph of moisture content and the statistical constant; (c) the graph of dry density and the statistical constant.

difference of the particle [14]. Therefore, adopting a single character parameter as a reference standard for evaluating the compaction degree is to be rejected owing to the lack of scientific rigor. This paper tries to apply the contour map to describe the variation rule of granular materials compaction degree using two Weibull parameters (the size and shape
TABle 3: Computational results for the physical and compaction behaviors of different dam granular materials (all of the field test samples).

\begin{tabular}{lcccc}
\hline Properties & & $\begin{array}{c}\text { Granular } \\
\text { material A }\end{array}$ & $\begin{array}{c}\text { Granular } \\
\text { material B }\end{array}$ & $\begin{array}{c}\text { Granular } \\
\text { material C }\end{array}$ \\
\hline \multirow{2}{*}{$\begin{array}{l}\text { Moisture } \\
\text { content (\%) }\end{array}$} & Maximum & 5.4 & 4.7 & 4.7 \\
& Minimum & 3.0 & 2.3 & 1.0 \\
\multirow{2}{*}{$\begin{array}{c}\text { Avy density } \\
\left(\mathrm{g} / \mathrm{cm}^{3}\right)\end{array}$} & Maximum & 2.5 & 3.4 & 2.7 \\
\hline \multirow{2}{*}{ Compaction } & Minimum & 2.13 & 2.31 & 2.39 \\
degree & Average & 2.14 & 2.20 & 2.33 \\
& Maximum & 0.93 & 0.97 & 2.36 \\
\hline & Minimum & 0.85 & 0.85 & 0.99 \\
& Average & 0.87 & 0.88 & 0.94 \\
\hline
\end{tabular}

parameters). As shown in Figure 9, the contours are distributed in an extremely scattered way and make great difficulty in concluding the dominant mathematical laws. However, when comparing the contour maps of three granular materials, the distribution is more messy and irregular when the particle size range is wider. Despite the influence of the particle itself, granular material samples with a wide range of particle sizes are much more susceptible to the effects of other factors in the process of rolling compaction. Above all, it is because the impacting factors are complex and difficult to control during the actual operation process that the approach based on quantitative experiment is unable to explore the explicit mathematical relationship between the Weibull parameters and relative density.

In general, various data indicators that can explain the difficulty in analyzing variables are provided with different data characteristics and different units. Data normalization is known to eliminate the impact of variable measurements, and it is a great assistance for discovering the recessive relationship between variables. When evaluating the structure status of granular material samples under the assumption that the particle is considered a sphere, the average level of particle size, scaling of particle groups' content, and the mutual arrangement of the particles are primary factors, and it is necessary to consider their influence. In this paper, these three evaluative dimensions of granular material structure are measured by the size parameter, the shape parameter, and the compaction degree, respectively. When a granular material system is compacted to a critical state and can no longer be tighter, it can be assumed that the impact of the three evaluative dimensions will remain in balance. Then, it can be supposed that the balance status is expressed by the following mathematical equation (granular materials A and B use (22) and granular material C uses (23)):

$$
\begin{gathered}
r_{0}^{*}+b^{*}+D_{\mathrm{r}}^{*}=1, \\
\text { or } r_{0}^{*}+b^{*}+D_{\mathrm{r}}^{*}=100 .
\end{gathered}
$$

Therefore, the data normalization referring to the ternary phase diagram can be processed by the following equations: 
TABLE 4: Characteristic values behind the PSD curves of different dam granular materials (only shows the analysis results of first 10 groups).

\begin{tabular}{|c|c|c|c|c|c|c|c|c|c|c|}
\hline \multirow{2}{*}{$\begin{array}{l}\text { Granular } \\
\text { material } \\
\text { type }\end{array}$} & \multirow[b]{2}{*}{ Number } & \multicolumn{3}{|c|}{$D$} & \multicolumn{2}{|r|}{$C_{\mathrm{U}}$} & \multicolumn{2}{|c|}{$C_{\mathrm{C}}$} & \multicolumn{2}{|c|}{ Weibull parameter } \\
\hline & & $\begin{array}{c}\text { Weibull } \\
\text { distribution }\end{array}$ & $\begin{array}{l}\text { Grading } \\
\text { analysis }\end{array}$ & $\begin{array}{c}\text { Error } \\
(\%)\end{array}$ & $\begin{array}{c}\text { Statistical } \\
\text { analysis }\end{array}$ & $\begin{array}{c}\text { Linear } \\
\text { interpolation }\end{array}$ & $\begin{array}{c}\text { Statistical } \\
\text { analysis }\end{array}$ & $\begin{array}{c}\text { Linear } \\
\text { interpolation }\end{array}$ & $\begin{array}{c}\text { Size } \\
\text { parameter }\end{array}$ & $\begin{array}{c}\text { Shape } \\
\text { parameter }\end{array}$ \\
\hline \multirow{10}{*}{ A } & S1 & 2.442 & 2.455 & -0.5 & 26.84 & 14.25 & 2.11 & 0.77 & 2.451 & 0.758 \\
\hline & S2 & 2.460 & 2.466 & -0.3 & 28.67 & 14.47 & 2.14 & 0.83 & 2.437 & 0.734 \\
\hline & S3 & 2.458 & 2.470 & -0.5 & 29.32 & 14.58 & 2.15 & 0.75 & 2.149 & 0.740 \\
\hline & S4 & 2.394 & 2.467 & -3.0 & 28.84 & 10.51 & 2.14 & 0.86 & 1.871 & 0.826 \\
\hline & S5 & 2.414 & 2.449 & -1.4 & 25.78 & 12.20 & 2.09 & 0.69 & 1.994 & 0.797 \\
\hline & S6 & 2.450 & 2.450 & 0.0 & 26.02 & 15.13 & 2.09 & 0.66 & 2.271 & 0.748 \\
\hline & S7 & 2.467 & 2.446 & 0.8 & 25.45 & 16.49 & 2.08 & 0.69 & 2.490 & 0.724 \\
\hline & S8 & 2.435 & 2.461 & -1.1 & 27.76 & 16.70 & 2.12 & 0.77 & 2.276 & 0.768 \\
\hline & S9 & 2.460 & 2.452 & 0.3 & 26.36 & 15.13 & 2.10 & 0.62 & 2.206 & 0.732 \\
\hline & S10 & 2.482 & 2.463 & 0.7 & 28.18 & 15.63 & 2.13 & 0.67 & 2.268 & 0.703 \\
\hline \multirow{10}{*}{ B } & S1 & 2.512 & 2.453 & 2.4 & 26.52 & 28.87 & 2.10 & 1.23 & 6.167 & 0.663 \\
\hline & S2 & 2.522 & 2.492 & 1.2 & 33.93 & 30.13 & 2.22 & 1.31 & 5.600 & 0.650 \\
\hline & S3 & 2.495 & 2.476 & 0.8 & 30.55 & 27.07 & 2.17 & 1.61 & 5.216 & 0.688 \\
\hline & S4 & 2.476 & 2.454 & 0.9 & 26.67 & 29.22 & 2.10 & 1.70 & 6.158 & 0.713 \\
\hline & S5 & 2.529 & 2.478 & 2.1 & 30.97 & 28.71 & 2.17 & 1.21 & 5.656 & 0.640 \\
\hline & S6 & 2.495 & 2.464 & 1.2 & 28.30 & 28.38 & 2.13 & 0.96 & 5.847 & 0.687 \\
\hline & S7 & 2.531 & 2.489 & 1.7 & 33.30 & 34.43 & 2.21 & 0.81 & 6.593 & 0.637 \\
\hline & S8 & 2.497 & 2.471 & 1.1 & 29.52 & 23.63 & 2.15 & 0.84 & 4.902 & 0.683 \\
\hline & S9 & 2.529 & 2.468 & 2.5 & 28.95 & 23.91 & 2.14 & 0.66 & 6.056 & 0.641 \\
\hline & $\mathrm{S} 10$ & 2.491 & 2.430 & 2.5 & 23.15 & 21.50 & 2.04 & 0.99 & 5.914 & 0.691 \\
\hline \multirow{10}{*}{ C } & S1 & 2.606 & 2.573 & 1.3 & 66.69 & 86.33 & 2.59 & 1.64 & 47.852 & 0.536 \\
\hline & S2 & 2.536 & 2.531 & 0.2 & 45.66 & 55.16 & 2.37 & 1.45 & 52.615 & 0.632 \\
\hline & S3 & 2.518 & 2.515 & 0.1 & 40.34 & 44.70 & 2.31 & 1.51 & 58.655 & 0.655 \\
\hline & S4 & 2.520 & 2.551 & -1.2 & 53.89 & 51.51 & 2.47 & 2.93 & 37.318 & 0.654 \\
\hline & S5 & 2.535 & 2.543 & -0.3 & 50.57 & 61.12 & 2.43 & 1.78 & 51.232 & 0.633 \\
\hline & S6 & 2.518 & 2.540 & -0.9 & 49.04 & 48.40 & 2.41 & 2.68 & 44.657 & 0.656 \\
\hline & S7 & 2.532 & 2.542 & -0.4 & 50.05 & 68.01 & 2.42 & 2.45 & 56.590 & 0.637 \\
\hline & S8 & 2.549 & 2.546 & 0.1 & 51.67 & 67.11 & 2.44 & 2.52 & 43.539 & 0.614 \\
\hline & S9 & 2.520 & 2.535 & -0.6 & 47.18 & 44.12 & 2.39 & 3.59 & 37.868 & 0.652 \\
\hline & $\mathrm{S} 10$ & 2.549 & 2.506 & 1.7 & 37.60 & 48.01 & 2.27 & 1.43 & 45.801 & 0.614 \\
\hline
\end{tabular}

Note. $D$ is the value of the statistical constant; $C_{\mathrm{U}}$ is the uniformity coefficient of the PSD curve; $C_{\mathrm{C}}$ is the curvature coefficient of the PSD curve.

$$
\begin{aligned}
& r_{0}^{*}=\frac{r_{0}}{r_{0}+b+D_{\mathrm{r}}}, \\
& b^{*}=\frac{b}{r_{0}+b+D_{\mathrm{r}}}, \\
& D_{\mathrm{r}}^{*}=\frac{D_{\mathrm{r}}}{r_{0}+b+D_{\mathrm{r}}} .
\end{aligned}
$$

Table 3 summarizes the statistical results for the physical and compaction behaviors of different dam granular materials including all of the field test samples. As shown in Table 3, the dry density of granular materials increases with the increasing content of coarse particles, where the granular material $\mathrm{C}$ is the maximum. The moisture content of granular materials is influenced by the particle size range and distribution (moisture content is an indirect reflection of the porosity of granular materials), and therefore, there is a vague relationship between the moisture content and the particle size distribution of granular materials. Here, the moisture content of granular materials decreases with the expanding range of particle size distribution, and it is also influenced by the continuity of particle gradation (various size of particles are rationally distributed). Therefore, the statistical results indicate that the relative density of granular material $\mathrm{C}$ is the largest and shows the best compaction performance. The compaction performance of granular material $\mathrm{A}$ is close to granular material $B$, due to the small difference in the particle size distribution.

The regularity in granular material structure after data normalization (Figure 10) can be described as that the impact of compaction degree will decline, whereas the impact of the size parameter increases. At the same time, the impact of the compaction degree will add up when the impact of the shape parameter increases. The analysis indicates that it is much more difficult to have a tight rolling compaction when the average particle size shows a growth trend for a certain type of dam granular materials. In a similar way, the dam granular materials of a sort will be easier to compact at the point where the shape parameter is in an increasing trend. As shown in Figures 10(d) and 10(e), the above regularity also exists when comparing the average level of different types of granular materials. Figure 10(d) shows that the average level of granular material $\mathrm{C}$, having a much wider range of particle sizes, is much larger than that of granular materials A and B. Figure 10(e) shows that 


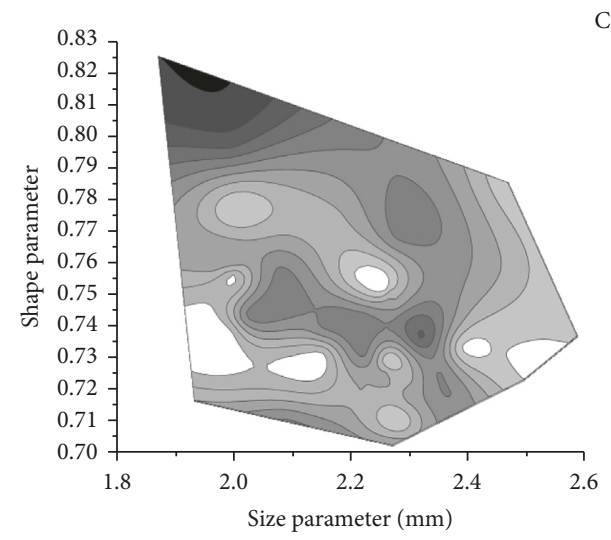

(a)
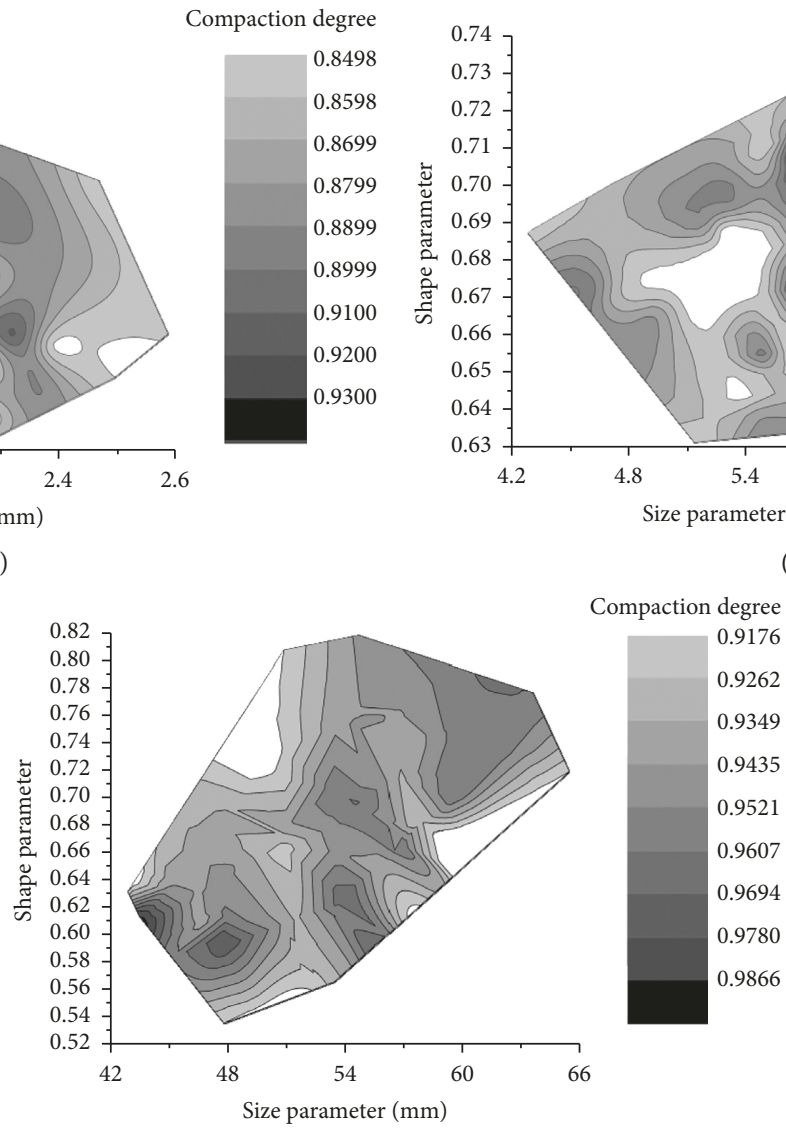

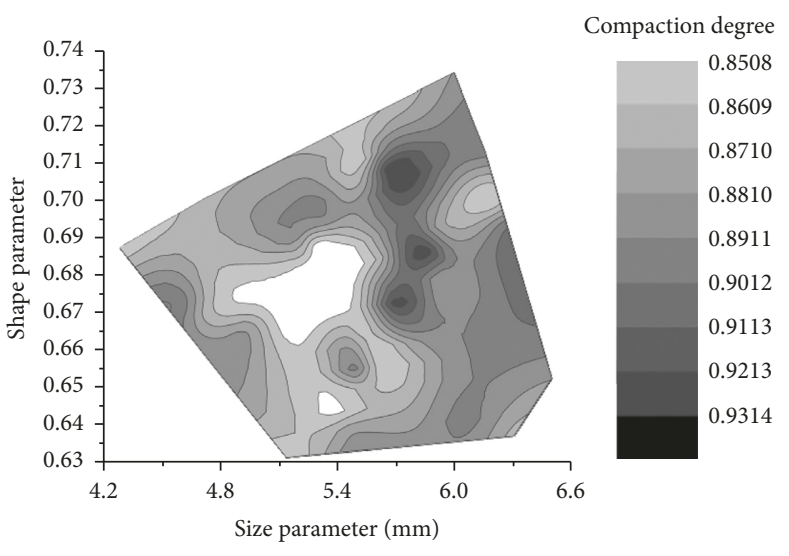

(b)

(c)

FIgURE 9: Relationship of the Weibull parameters and the compaction degree of granular materials: (a) A; (b) B; (c) C.

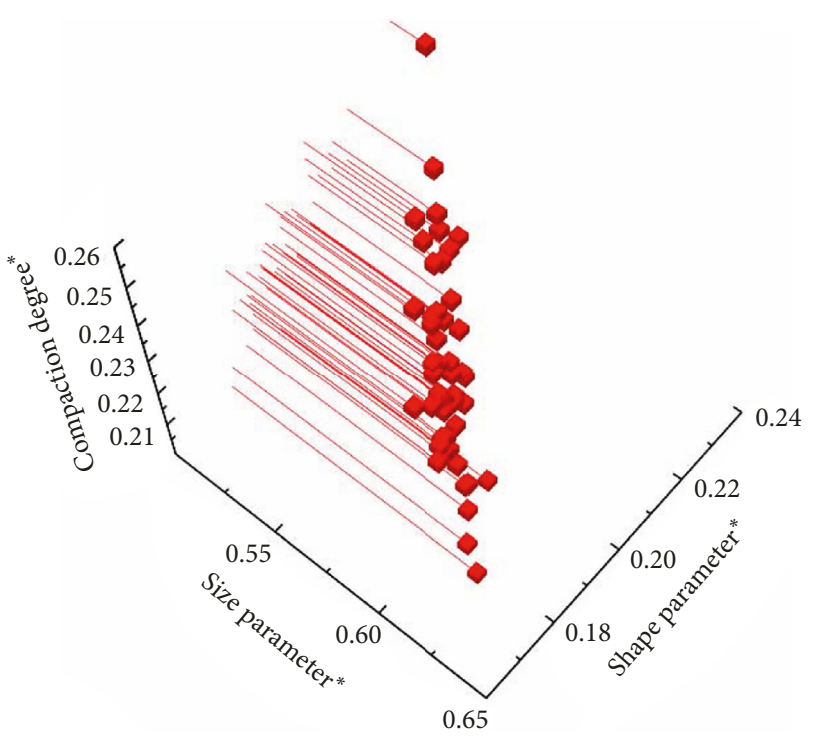

(a)

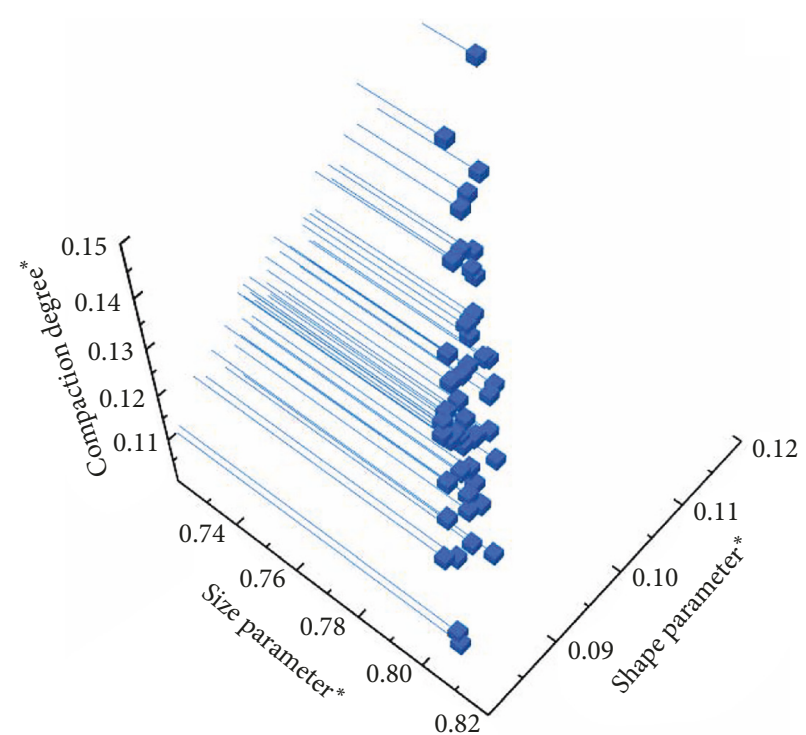

(b)

Figure 10: Continued. 


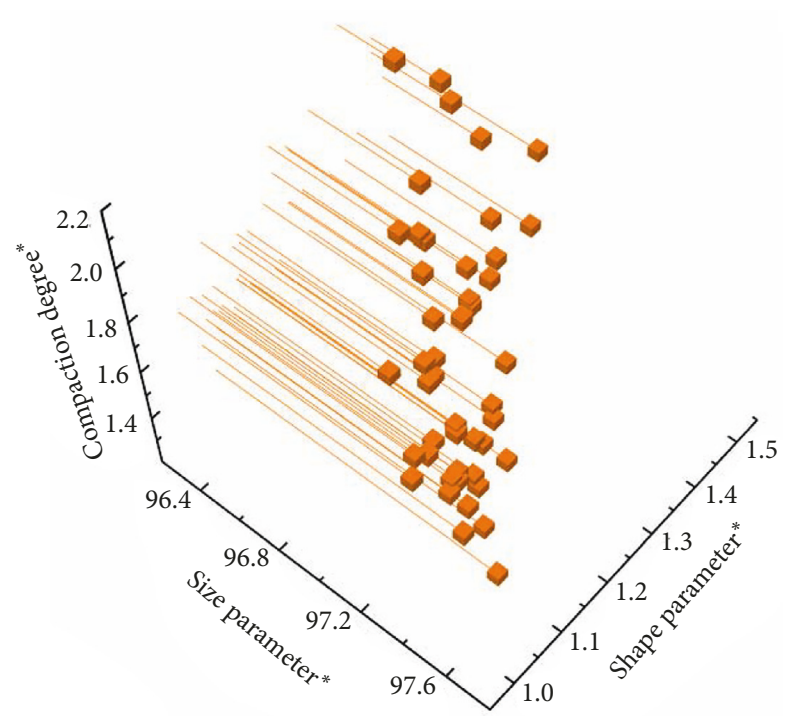

(c)

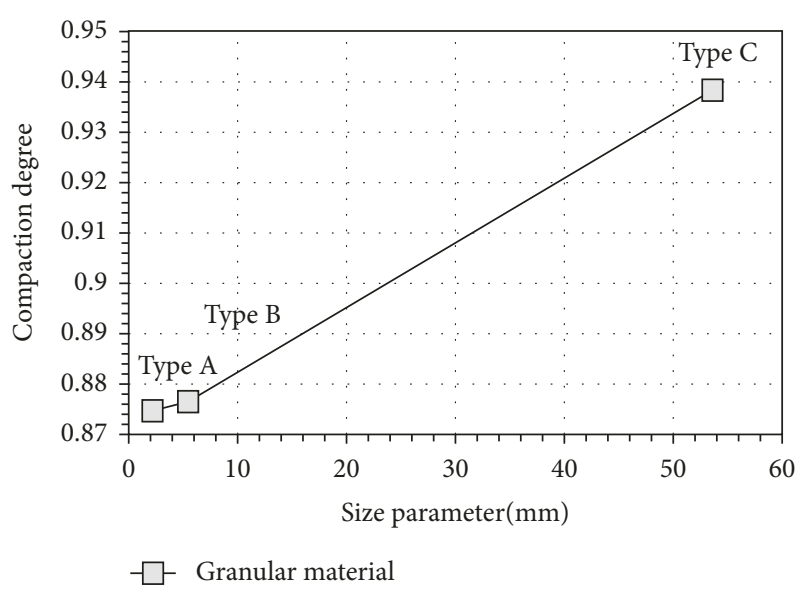

(d)

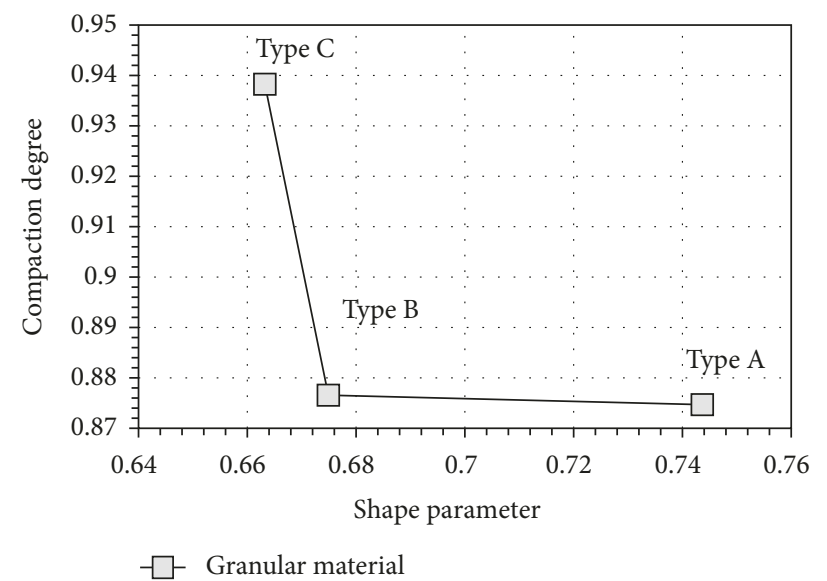

(e)

FIGURE 10: Relationship between the Weibull parameters and the compaction degree of granular materials after normalization: (a) granular material A; (b) granular material B; (c) granular material C; (d) correlation between the size parameter and the compaction degree of different granular materials; (e) correlation between the shape parameter and the compaction degree of different granular materials (size parameter* represents the value of the size parameter after normalization; shape parameter* represents the value of the shape parameter after normalization; compaction degree* represents the value of the compaction degree after normalization).

granular material $\mathrm{C}$ has a larger shape parameter separation between granular materials $\mathrm{A}$ and $\mathrm{B}$. There is a closer contact between large and small particles when in a wider range of particle sizes. It further illustrates that the particle size range of granular materials can dramatically improve the compaction effect for artificial materials with a good grading. There are sufficient result foundations explaining that the size parameter has a positive correlation with the compaction degree and the shape parameter has a negative correlation with the compaction degree.

\section{Discussion and Conclusions}

The statistical analysis ensures the validity of the theoretical basis in quantifying the physical and compaction characteristics of granular materials on different spatial scales [36]. In regard to this possibility, this paper discusses the use of the Weibull distribution function for describing the PSD of granular materials with artificial grading. It is well known that a two-parameter Weibull distribution function is capable of characterizing the PSD of soil mixtures [34]. However, the soil samples the paper uses are from the dam granular materials with artificial grading. To ensure the precision and scientific foundation, it is found that there is little error between the two different calculation methods of statistical constant (from analysis and based on the Weibull distribution), which states that the use of the Weibull distribution function is feasible here. A two-parameter Weibull distribution function has size parameter $r_{0}$ and shape parameter $b$. The size parameter is generally considered to be the average value of particle size. Meanwhile, from (19), there is a definite mathematical equation between the slope of any point on the PSD curves and the ratio of the cumulative contents of the particles' size less than two specific 
values. The shape parameter is characterizing the shape of the Weibull function curve. When using the Weibull function to fit the PSD curve, it is obvious that the shape parameter is connected with the particle size range, or more precisely, the scaling distribution of the particle group, and the larger the size range is, the less the shape parameter will be. However, this study is based on the assumption that all particles act as ideal spheres, though the relationship between particle shape and the critical state has been discussed [6]. Therefore, further study needs to take these factors into consideration, including the relationship between the shape parameter and the grading scaling distribution as well as the impact of particle shape on compaction.

This paper explores the physical and compaction properties of granular materials with four parameters (relative density $D_{\mathrm{r}}$, statistical constant $D$, and Weibull parameters (size parameter $r_{0}$ and shape parameter $b$ )). These parameters $\left(D_{\mathrm{r}}, r_{0}\right.$, and $\left.b\right)$ provide a uniform data standard for comparing measured values between granular material samples of different types. However, the statistical constant is not qualified to do this because the erratic fluctuation of statistical results appears as a stagger phenomenon on statistical constant ranges of different types. The stagger scope is connected with the particle size range, which leads to invalid comparisons of the statistical constants from different types of granular materials samples. The statistical constant can only reflect the integral level of certain granular materials, and it has the ability to show the type discrepancies (Figure 8(c)). Therefore, the paper uses these three parameters $D_{\mathrm{r}}, r_{0}$ and $b$ to get a comprehensive analysis of the structural status of three types of granular materials with the assistance of the statistical constant.

There is a direct and close link between PSD curve and statistical constant. The statistical constant can represent the variation of PSD curves, and the characteristic coefficients $\left(C_{\mathrm{U}}\right.$ and $\left.C_{\mathrm{C}}\right)$ of the PSD curve can be calculated by the statistical constant under postulated conditions. It can be said that the statistical constants are likely to be an indicative parameter for verifying the quality of artificial grading. The regularity of the Weibull parameters and compaction degree in different granular material samples of the same type and the regularity in different types are consistent, making a contribution to providing significant guidance on how to improve compaction during actual construction. However, the mechanism by which Weibull parameters influence compaction process needs to be further explored.

The final results are shown with some fluctuations. First, the granular material samples the paper uses are fill materials in construction and all are considered to have good grading; the analysis results of the compaction properties have limitations. The lack of a comparison between good and bad grading distribution calls for future research setting up a series of control groups. Second, measurement error, especially the significance figure caused in calculation, is existed in dry density and compactness of granular materials, and the measurement is achieved by engineering personnel, which causes that the paper cannot reach an accurate expression of how Weibull parameters influence compaction properties. Therefore, the future research needs to make a better measurement of compaction degree (1) considering the use of a method of entropy approach for adding another evaluating indicator of the PSD curve and (2) viewing the particle of granular materials as a rectangular parallelepiped shape or a dodecahedron of which four surfaces are octagon and eight surface are triangle and making formula derivations for obtaining statistical constants under different assuming conditions.

\section{Data Availability}

The data used to support the findings of this study were supervised and licensed by the Hydropower Development Company and so cannot be made freely available. Access to these data will be considered by the author upon request, with permission of the Hydropower Development Company.

\section{Conflicts of Interest}

The authors declare that there are no conflicts of interest regarding the publication of this paper.

\section{Acknowledgments}

The authors gratefully acknowledge the support of the Youth Science and Technology Fund of Sichuan Province (2016JQ0011) and the Key Project of the Power Construction Corporation of China (ZDZX-5).

\section{References}

[1] J. C. Davis and N. J. Hoboken, Statistics and Data Analysis in Geology, Wiley, New York, NY, USA, 3rd edition, 2012.

[2] G. Marketos and M. D. Bolton, "Quantifying the extent of crushing in granular materials: a probability-based predictive method," Journal of the Mechanics and Physics of Solids, vol. 55, no. 10, pp. 2142-2156, 2007.

[3] D. Hillel, Fundamentals of Soil Physics, Academic Press, New York, NY, USA, 1st edition, 1980.

[4] B. Caicedo, M. Ocampo, and L. E. Vallejo, "Modelling comminution of granular materials using a linear packing model and Markovian processes," Computers and Geotechnics, vol. 80, pp. 383-396, 2016.

[5] J. P. Hyslip and L. E. Vallejo, "Fractal analysis of the roughness and size distribution of granular materials," Engineering Geology, vol. 48, no. 3-4, pp. 231-244, 1997.

[6] J. Yang and X. D. Luo, "Exploring the relationship between critical state and particle shape for granular materials," Journal of the Mechanics and Physics of Solids, vol. 84, pp. 196-213, 2015.

[7] B. B. Mandelbrot, The Fractal Geometry of Nature, Macmillan Publishes Limited, London, UK, 1st edition, 1983.

[8] J. J. Wang, D. Zhao, Y. Liang, and H. B. Wen, "Angle of repose of landslide debris deposits induced by 2008 Sichuan Earthquake," Engineering Geology, vol. 156, pp. 103-110, 2013.

[9] M. Rieu and G. Sposito, "Fractal fragmentation, soil porosity, and soil water properties: I. Theory," Soil Science Society of America Journal, vol. 55, no. 5, pp. 1231-1238, 1991.

[10] Z. Y. Ma, F. N. Dang, and H. J. Liao, "Numerical study of the dynamic compaction of gravel soil ground using the discrete element method," Granular Matter, vol. 16, no. 6, pp. 881-889, 2014. 
[11] G. Lumay and N. Vandewalle, "Compaction of anisotropic granular materials: experiments and simulations," Physical Review E, vol. 70, no. 1, 2004.

[12] H. S. Thilakasiri, M. Gunaratne, G. Mullins, P. Stinnette, and B. Jory, "Investigation of impact stresses induced in laboratory dynamic compaction of soft soils," International Journal for Numerical and Analytical Methods in Geomechanics, vol. 20, no. 10, pp. 753-767, 1996.

[13] J. B. Knight, C. G. Fandrich, C. N. Lau, H. M. Jaeger, and S. R. Nagel, "Density relaxation in a vibrated granular material," Physical Review E, vol. 51, no. 5, pp. 3957-3963, 1995.

[14] N. Vandewalle, G. Lumay, O. Gerasimov, and F. Ludewig, "The influence of grain shape, friction and cohesion on granular compaction dynamics," European Physical Journal E, vol. 22, no. 3, pp. 241-248, 2007.

[15] P. Lu, I. F. Jefferson, M. S. Rosenbaum, and I. J. Smalley, "Fractal characteristics of loess formation: evidence from laboratory experiments," Engineering Geology, vol. 69, no. 3-4, pp. 287-293, 2003.

[16] M. A. Martín, M. Reyes, and F. J. Taguas, "Estimating soil bulk density with information metrics of soil texture," Geoderma, vol. 287, pp. 66-70, 2017.

[17] M. A. Martín, M. Reyes, and F. J. Taguas, “An entropy like parameter of particle size distributions as packing density index in complex granular media," Granular Matter, vol. 19, p. $9,2017$.

[18] M. W. Clark, "Some methods for statistical analysis of multimodal distributions and their application to grain-size data," Journal of the International Association for Mathematical Geology, vol. 8, no. 3, pp. 267-282, 1976.

[19] S. W. Tyler and S. W. Wheatcraft, "Application of fractal mathematics to soil water retention estimation," Soil Science Society of America Journal, vol. 53, no. 4, pp. 987-996, 1989.

[20] E. Perfect and B. D. Kay, "Fractal theory applied to soil aggregation," Soil Science Society of America Journal, vol. 55, no. 6, pp. 1552-1558, 1991.

[21] S. W. Tyler and S. W. Wheatcraft, "Fractal scaling of soil particle-size distributions: analysis and limitations," Soil Science Society of America Journal, vol. 56, no. 2, pp. 362-369, 1992.

[22] M. Rieu and G. Sposito, "Fractal fragmentation, soil porosity, and soil water properties: II. Applications," Soil Science Society of America Journal, vol. 55, no. 5, pp. 1239-1244, 1991.

[23] A. N. Anderson, A. B. McBratney, and J. W. Crawford, "Applications of fractals to soil studies," Advances in Agronomy, vol. 63, no. 8, pp. 1-76, 1997.

[24] E. Perfect and B. D. Kay, "Applications of fractals in soil and tillage research: a review," Soil and Tillage Research, vol. 36, no. 1-2, pp. 1-20, 1995.

[25] X. Wang, S. Liu, and G. Liu, "Fractal characteristics of soils under different land-use patterns in the arid and semi-arid regions of the Tibetan Plateau, China," Wuhan University Journal of Natural Science, vol. 134, no. 4, pp. 56-61, 2005.

[26] N. Prosperini and D. Perugini, "Particle size distributions of some soils from the Umbria Region (Italy): fractal analysis and numerical modeling," Geoderma, vol. 145, no. 3-4, pp. 185195, 2008.

[27] S. Yu and C. T. Oguchi, "Role of pore size distribution in salt uptake, damage, and predicting salt susceptibility of eight types of Japanese building stones," Engineering Geology, vol. 115, no. 3-4, pp. 226-236, 2010.

[28] F. Yang, Z. Ning, and H. Liu, "Fractal characteristics of shales from a shale gas reservoir in the Sichuan Basin, China," Fuel, vol. 115, no. 1, pp. 378-384, 2014.
[29] S. Shao, X. G. Yang, and J. W. Zhou, "Numerical analysis of different ventilation schemes during the construction process of inclined tunnel groups at the Changheba Hydropower Station, China," Tunnelling and Underground Space Technology, vol. 59, pp. 157-169, 2016.

[30] D. L. Turcotte, "Fractals and fragmentation," Journal of Geophysical Research-Solid Earth, vol. 91, no. B2, pp. 19211926, 1986.

[31] H. P. Xie, Fractals in Rock Mechanics, CRC Press, Boca Raton, FL, USA, 1993.

[32] L. Kittleman, "Application of Rosin's distribution in sizefrequency analysis of clastic rocks," Journal of Sedimentary Research, vol. 34, no. 3, pp. 483-502, 1964.

[33] W. Weibull, "A statistical theory of the strength of materials," in Proceedings of the NR151 the Royal Swedish Institute for Engineering Research, Stockholm, Sweden, 1939.

[34] Y. S. Cheong, G. K. Reynolds, A. D. Salman, and M. J. Hounslow, "Modelling fragment size distribution using two-parameter Weibull equation," International Journal of Mineral Processing, vol. 74, no. 50, pp. 227-237, 2004.

[35] F. Casini, G. M. Viggiani, and S. M. Springman, "Breakage of an artificial crushable material under loading," Granular Matter, vol. 15, no. 5, pp. 661-673, 2013.

[36] H. Millan, M. Gonzalez-Posada, M. Aguilar, J. Domınguez, and L. Cespedes, "On the fractal scaling of soil data. Particlesize distributions," Geoderma, vol. 117, no. 1-2, pp. 117-128, 2003.

[37] Y. X. Xiao, C. F. Lee, and S. J. Wang, "Particle-size distribution of interlayer shear zone material and its implications in geological processes-a case study in China," Engineering Geology, vol. 66, no. 3-4, pp. 221-232, 2002.

[38] Y. Z. Su, H. L. Zhao, W. Z. Zhao, and T. H. Zhang, "Fractal features of soil particle size distribution and the implication for indicating desertification," Geoderma, vol. 122, no. 1, pp. 43-49, 2004. 


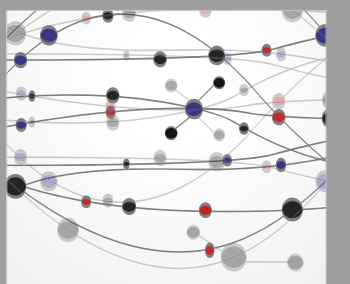

The Scientific World Journal
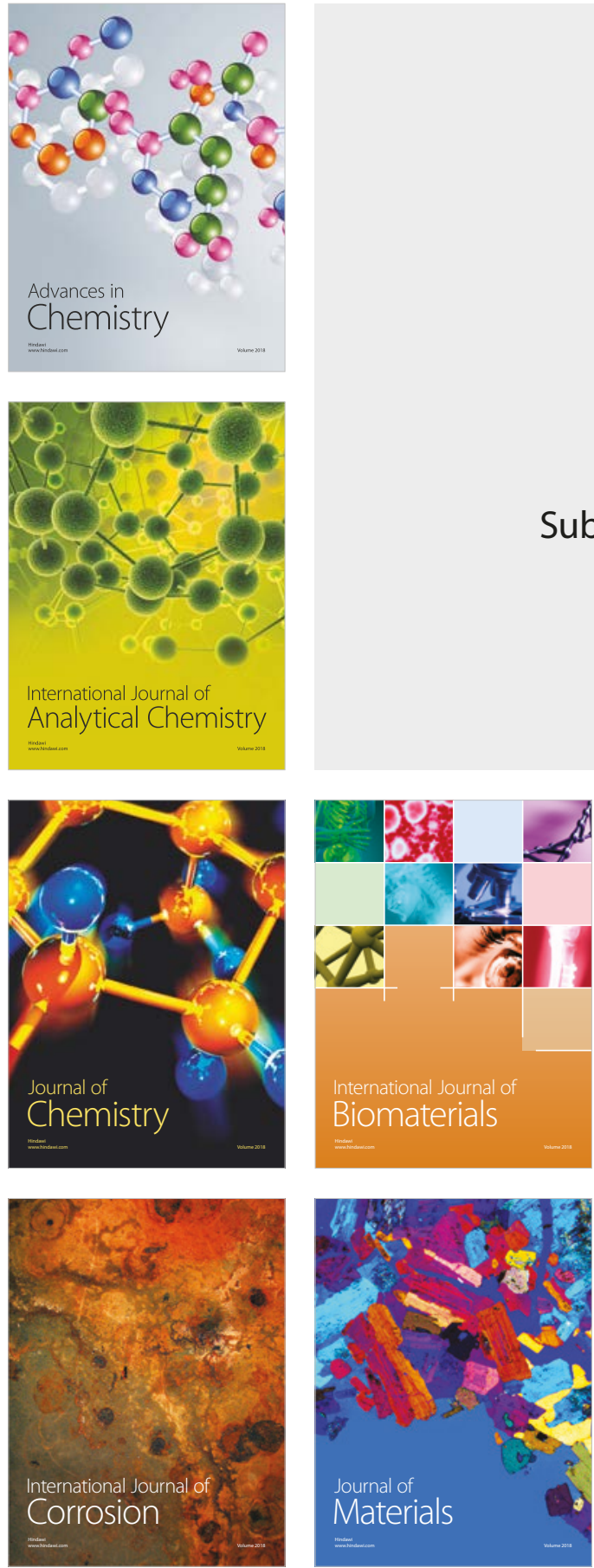

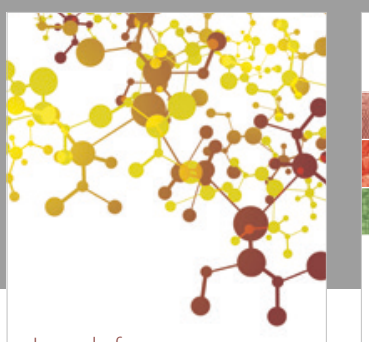

Journal of

Applied Chemistry
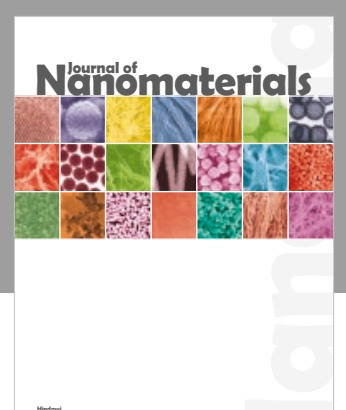

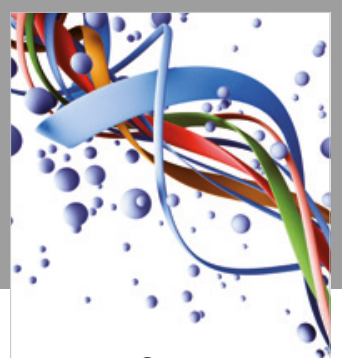

Scientifica

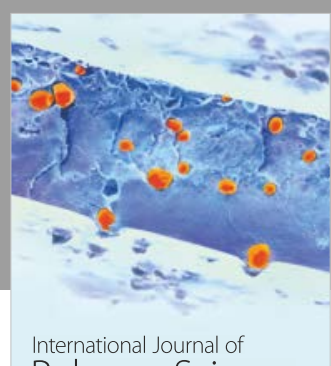

Polymer Science

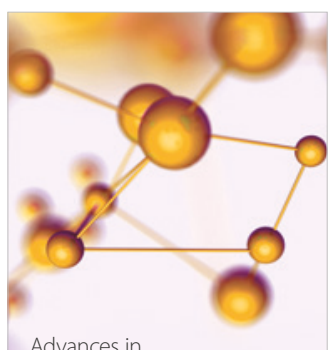

Physical Chemistry
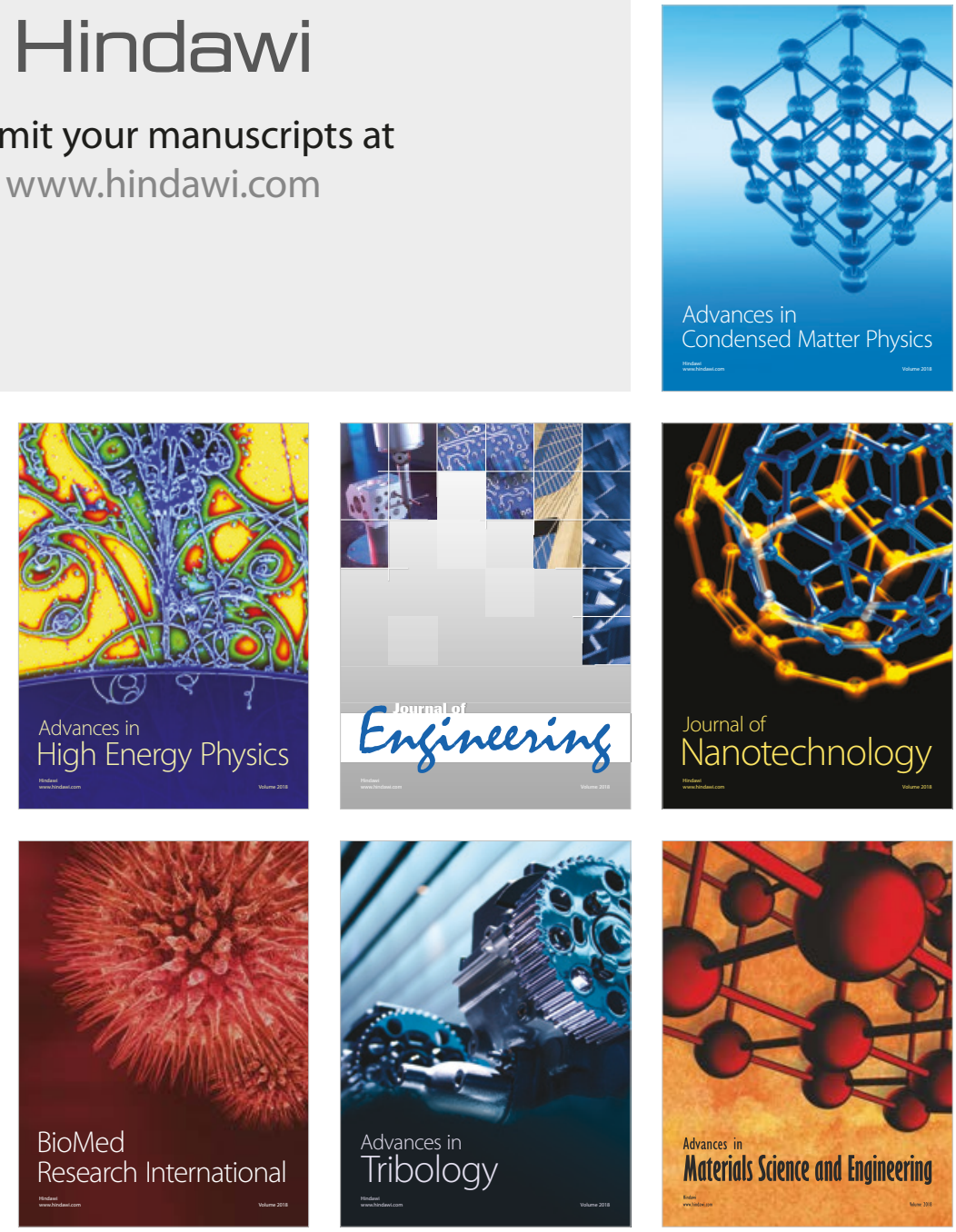